\title{
State Opioid Response (SOR) to the Opioid Crisis Grant Final Evaluation
}

JG Research \& Evaluation | Bozeman, MT 


\section{REPORT INFORMATION AND ACKNOWLEDGMENTS}

This report was written by Matthew R. Filteau and Brandn Green of JG Research \& Evaluation.

The authors would like to thank all of the respondents who took the time to be interviewed for this report. Thank you as well to Joclynn Ware (AMDD SOR grant manager), Bobbi Perkins (Prevention Bureau Chief), and Ki-Ai McBride (Opioid Prevention Program Manager).

This study was funded by the Montana State Opioid Response (SOR) grant from the Substance Abuse and Mental Health Services Administration (SAMHSA), U.S. Department of Health and Human Services (HHS) to the Addictive and Mental Disorders Division (AMDD), Montana Department of Public Health and Human Services (DPHHS).

The study was reviewed by Western IRB and found to be exempt under 45 CFR $\S$ 46.104(d)(2).

The views and opinions expressed in this report are those of the authors and do not reflect the official policy or position of any agency of the government of the State of Montana.

This report was finalized in July of 2021.

\section{CITATIONS OF THIS PAPER}

Please use the following format when citing this paper:

Filteau, M.R. and Green, B. (2021). State Opioid Response to the Opioid Crisis Grant Final Evaluation. JG Research and Evaluation. DOI: 10.36855/SOR2021.5. Available at jgresearch.org/ publications. 


\section{TABLE OF CONTENTS}

STUDY SUMMARY IV

SECTION I: BACKGROUND ON MEDICATION-ASSISTED TREATMENT AND THE STATE

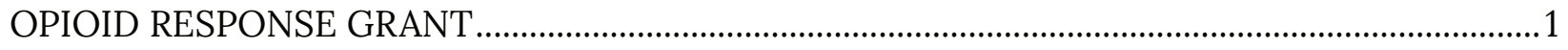

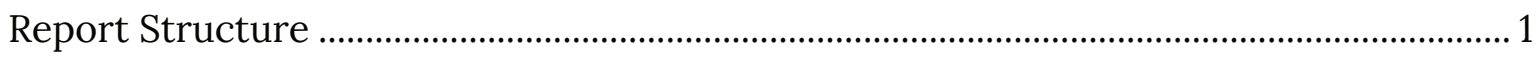

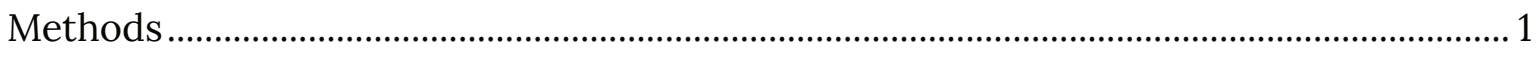

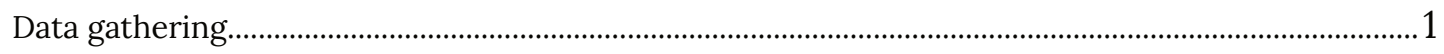

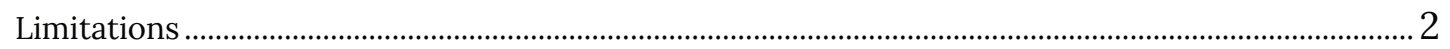

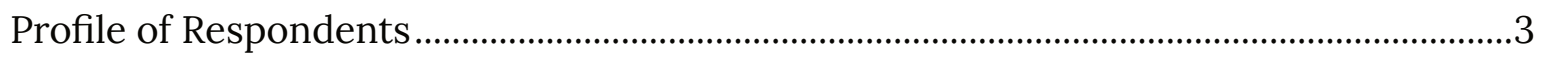

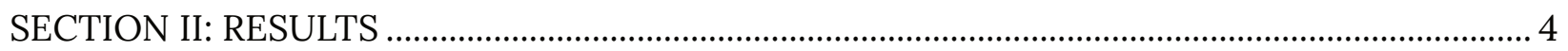

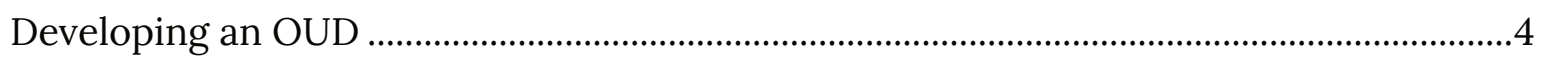

Continuing or Improving Health Benefits and Outcomes for Patients .............................5

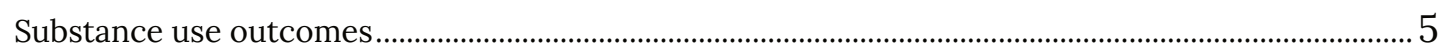

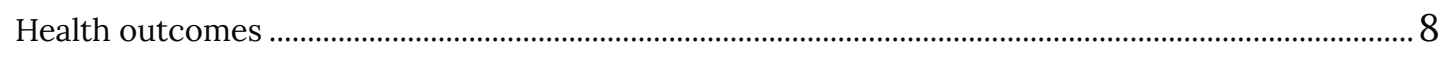

Providing care to special populations ................................................................................................

Program retention and reenrollment............................................................................................... 14

Barriers to successful outcomes in MAT programs .................................................................................... 16

Continuing Program Activities or Core Elements of the Original Intervention ............. 21

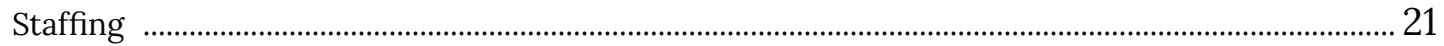

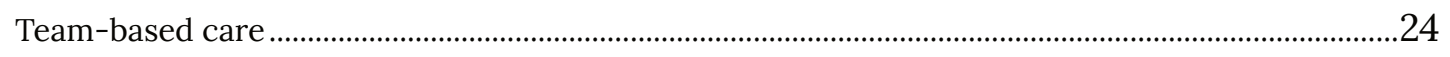

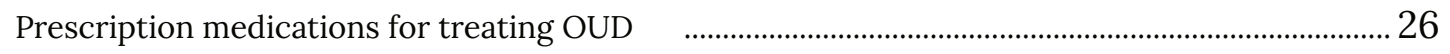

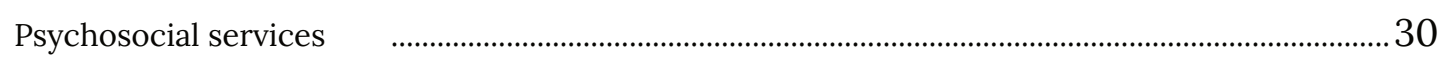

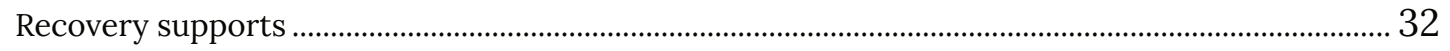

Maintaining Organizational Practices, Procedures, and Policies …................................. 33

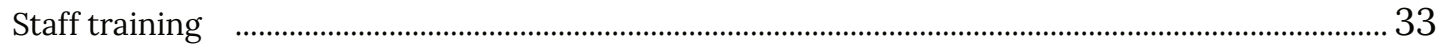

Processes for MAT programs …………………………………………………………………... 35

Tracking of program activities and fidelity …………………………………………………..... 36

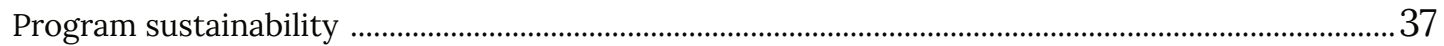

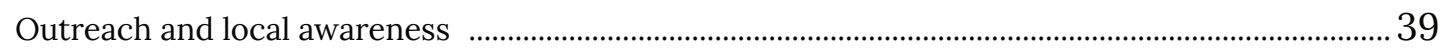

Maintaining Community-Level Partnerships and Coalitions ........................................... 41

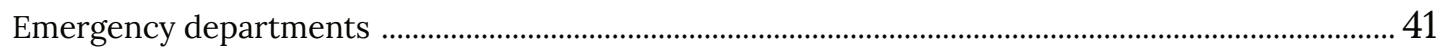

Criminal justice (jail, drug court, police) .............................................................................................42

Other collaborations: CPS, tribes, Ideal Options, and needle exchanges ............................................ 45

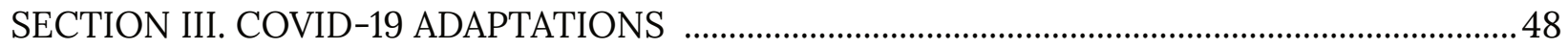

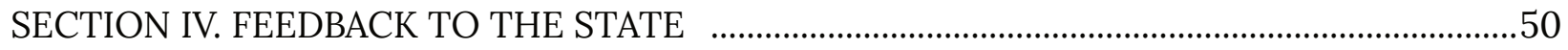

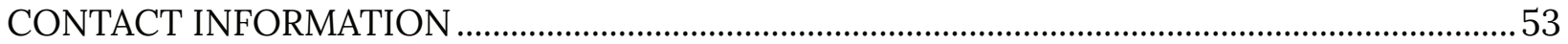




\section{STUDY SUMMARY}

The State Opioid Response (SOR) program began in September 2019. Data for this report was collected during the summer of 2020, with a primary goal of understanding how sites with SOR funding were progressing in providing medication-assisted treatment (MAT) services for individuals with opioid use disorders (OUDs).

The majority of sites that participated in SOR also participated in the State Targeted Response (STR) program and had multiple years of experience in providing MAT at the time of the process evaluation. The study design reflected the levels of site experience. The primary themes investigated through interviews and qualitative analysis were (1) continuing or improving health benefits and outcomes for patients, (2) continuing program activities and core elements of the original intervention, (3) maintaining organizational practices and procedures, and (4) maintaining community-level partnerships and collaborations. These themes, which reflect key components of program sustainability, structure the results presented in this report.

\section{Continuing or Improving Health Benefits and Outcomes for Patients}

According to providers, the true measure of the success of their MAT programs consists of positive changes in their patients' everyday lives: sobriety, healthy relationships, healthy pregnancies, steady employment, use of healthcare and attention to health and well-being. Patients confirmed these life-altering benefits. Enrollment in MAT empowered patients to change their priorities, become more involved with their families, pursue job and financial security, and renew the passions they had held before opioid use dominated their lives.

MAT program staff credited their team-based approach to care as integral to building trust and establishing rapport with patients. Similarly, patients described a caring, respectful, helpful and professional staff supportive of the MAT program's policies and procedures. Both patients and staff discussed how wait times, readiness and program immersion affected adherence to program components.

In addition to reporting on successful outcomes, patients and staff shared barriers to success. These included a lack of local transportation options, the social conditions facing patients, and some difficulties in learning about and accessing treatment. Staff tried to minimize these barriers by collaborating and integrating care with outside agencies, including Child Protective Services (CPS), detention facility staff, and drug courts. Providers described methamphetamine use among patients as devastating to many patients' recovery. Engaging patients remains an ongoing challenge, as many patients report struggling to fully participate in the program owing to the program's schedule and structure.

\section{Continuing Program Activities or Core Elements of the Original Intervention}

Program staff emphasized the need for a cohesive team. They valued opportunities to learn from staff across the state and sought access to trainings, especially Montana Primary Care Association (MPCA) trainings on opioids, stimulant use disorder and cultural sensitivity.

Staffing within MAT clinics was a common topic of concern, as many sites sought to increase the number of waivered providers internal to their program and increase the capacity of those providers. Staff noted the importance of the MAT registered nurse (RN) for daily operations. The peer support specialist role was the most varied, with some programs choosing to employ internal peer support staff, others opting for external, contracted peer support, and a few electing to not use peer support specialists within their program. 
Suboxone is the most frequently prescribed medication at SOR clinics. Sometimes they prescribe other medications, such as Sublocade, when a patient's life choices and patterns suggest they would struggle with adhering to a Suboxone regimen. Staff commented on the need to consider how to expand use of and access to Naloxone.

Providers often reported difficulty engaging patients in behavioral health and group therapy. This was particularly challenging during the COVID-19 pandemic as social distancing and physical isolation plagued many Montanans. The digital divide constrained many patients' access to care as treatment transitioned from in person to online.

Maintaining Organizational Practices, Procedures and Policies

Staff reported on efforts to collaborate and keep all their medical, nursing and counseling staff updated and informed on changes with patients. Cost and billing of insurance were the foremost concerns. Sites with a low waiver capacity (30 patients) struggled to retain a waivered provider, and staff commented that better training and information sharing would aid program sustainability.

\section{Maintaining Community-Level Partnerships and Coalitions}

Sites experienced a seamless transition from STR to SOR and reported increasing interest in the program among potential patients. The SOR phase is marked by more time spent networking with local organizations and less time spent directly recruiting new patients. SOR sites sought to collaborate with organizations within their communities, including hospitals, the criminal justice system, Child Protective Services (CPS), tribes, Ideal Options and needle exchanges. Providers and patients differed in their perceptions of outreach and local awareness. Staff at SOR sites described launching outreach and advertising campaigns, but as in the STR phase, patients still said they lacked knowledge of the MAT clinics and had difficulty learning about services within the community.

\section{Program Successes and Challenges}

SOR MAT programs empower patients to pursue recovery and live healthy fulfilling lives that lead to sobriety, healthy relationships, healthy pregnancies, steady employment, and attention to their health and well-being. Patients also realize the benefits by being more active in the lives of their family members, experiencing job and financial security, and reviving their passions, hobbies, and interests.

Many of the challenges for SOR programs are external to the programs themselves and reflect broader disadvantages throughout many communities in Montana. The lack of reliable transportation exacerbates the geographic isolation so many patients face. The inability of telehealth to transcend this barrier speaks to the broader structural constraints facing locations and individuals throughout Montana. Unstable housing coupled with the lack of recovery housing, lack of transportation paired with the connectivity gap, cooccurring disorders, and detrimental social relationships affect patients' ability to succeed in the program. Learning about the existence of IMAT programs and accessing treatment are regarded as two of the hardest parts of treatment; these challenges may be resolved by further integrating care into other healthcare settings and agencies. 


\section{SECTION I: BACKGROUND ON MEDICATION-ASSISTED TREATMENT AND THE STATE OPIOID RESPONSE GRANT}

The State Opioid Response (SOR) grant funding was awarded to the Addictive and Mental Disorders Division (AMDD) of the State of Montana Department of Public Health and Human Services (DPHHS) by the Substance Abuse and Mental Health Services Administration (SAMHSA). The grant program aimed to support states in addressing the opioid crisis by "increasing access to treatment, reducing unmet treatment need, and reducing opioid overdose-related deaths through the provision of prevention, treatment and recovery activities for opioid use disorder (OUD)" (SAMHSA, 2018). Grant activities began in fall 2019.

The goals of the SOR grant program were to efficiently and effectively use the funding to prevent opioid-involved deaths and to expand access to prevention, treatment, and recovery services for those with an OUD. This report concentrates only on the efforts to support Goal 1: Increase access to medications for opioid use for underserved populations of focus throughout Montana.

\section{Report Structure}

The SOR evaluation was designed to continue to document the progress AMDD did or did not make on the outcomes associated with the treatment goals. This report draws on two waves of data collection, conducted during STR and SOR, with staff and patients at sites providing MAT and offers a distinctive approach to monitoring, and continued practices at those sites. In addition to the results presented in this report, additional special studies were undertaken under the SOR grant program to complement the study of MAT site practices and perspectives. These additional reports address the following topics: veterans accessing MAT, pregnant women accessing MAT, the impact of stigma on MAT utilization, Narcan utilization among first responders, and use of MAT in detention facilities.

\section{Methods}

\section{Data gathering}

The primary mode of data collection for the process evaluation consisted of interviews. Interviews with staff were completed either one on one or in small groups. The research team provided each site with a set of requested interviewees. This list included the following:

1. SOR care coordinator

2. SOR program manager

3. Behavioral health providers (one or two), including social workers and therapists

4. Prescribing providers (one or two), including medical doctors (MDs), doctors of osteopathy (DOs), advanced practice registered nurses (APRNs), and pharmacologists

5. Executive leadership at your site

6. Peer Support Specialists (PSSs) who work with your site

7. Any medical staff who have been resistant to MAT

8. A few current and former patients (that is, patients who left the program) 
There were slight variations in the final interviewees at each site owing to issues of availability and differences in MAT team staff structure. All sites included interviews with at least one patient. We were unable to speak with any former patients who had left a program. The care coordinator or program director at each location served as the point of contact, finalized the agenda, and recruited all interviewees at each site. The locations of the patient respondents are listed in Table 1. Locations of Patient Interviewees and the provider interviews for each site are listed in Table 2.

The primary means of data collection from patients consisted of in-depth interviews with MAT patients at 6 SOR sites in Montana. Researchers contacted participants using a formal recruitment script by telephone. We contacted patients a maximum of 5 times, and if the potential participant did not reply, they were marked as "no response." Interviewers obtained verbal consent for the interview before proceeding with the interview process. Owing to COVID-19, interviews were conducted over the phone with each participant's consent, audio recorded, and transcribed verbatim. All interviews were conducted confidentially, and all data in this report is reported anonymously.Each interview took approximately one hour. A semi-structured interview guide was used to collect answers to both open and close-ended survey questions. Separate interview guides for patients and providers were created by the research team and reviewed by AMDD staff. All data analysis used qualitative coding based on an inductive coding scheme created by the research team to correspond to an adaptation of research-based frameworks to examine program sustainability. The research team identified additional deductive codes during the process of reviewing the transcripts. All interviews and small groups were audio recorded, transcribed, and coded by two members of the research team. This process was intended to ensure a higher degree of coding reliability. All qualitative data analysis was completed in NVivo.

In addition to the qualitative data collected at each site, we asked the primary prescriber and the behavioral health care director (or comparable staff) to complete a MAT program composition survey. This brief survey contained open-ended and yes/no questions about 17 elements of a MAT program. The survey was informed by the ASAM National Practice Guideline for the Use of Medications in the Treatment of Addiction Involving Opioids (ASAM, 2015) and the SAMHSA Treatment Improvement Protocol 63: Medications for Opioid Use Disorder (SAMHSA, 2018). Results from this survey were used to produce the site profile tables that are in in a separate report that focuses on understanding the structure of SORfunded programs in contrast to non-SOR-funded medication for opioid use disorder (MOUD) programs in Montana.

\section{Limitations}

The main limitation of this study was that each patient participant was selected by healthcare staff at each location. Nonetheless, participants provided candid responses, both positive and negative, on their MAT program. 


\section{Profile of Respondents}

Researchers conducted 22 patient interviews; the locations of the patient interviewees are shown in Table 1. Locations of Patient Interviewees. Researchers also completed 52 interviews of providers, whose locations and staff positions are listed in Table 2. Location of Provider Interviewees.

Table Table 1. Locations of Patient Interviewees

\begin{tabular}{lc}
\multicolumn{1}{c}{ Clinic } & Number of Patients \\
\hline Big Horn & 5 \\
\hline Butte & 4 \\
\hline Bullhook & 4 \\
\hline Hamilton & 3 \\
\hline Missoula & 5 \\
\hline Polson & 1 \\
\hline Total & 22
\end{tabular}

Table 2. Location of Provider Interviewees ${ }^{1}$

\begin{tabular}{llc}
\multicolumn{1}{c}{ Clinic } & \multicolumn{1}{c}{ Staff Positions } & $\begin{array}{c}\text { Total Interviewees } \\
\text { bv Site }\end{array}$ \\
\hline Big Horn and Ashland & MAT RN, care coordinator, BH director, CEO, NP, RN & 8 \\
\hline Browning and CMS & $\begin{array}{l}\text { BH specialist, care manager, CEO, LAC, peer support } \\
\text { specialist, prescribing provider }\end{array}$ & 8 \\
\hline Havre & $\begin{array}{l}\text { Administrator, care coordinator, LACs, prescribing } \\
\text { provider, RN, NP, RN care coordinator }\end{array}$ & 10 \\
\hline Butte & CEO, CMO, COO, prescribing provider, pharmacist, & 9 \\
Helena & NP, RN care coordinator & 4 \\
Kalispell & BH director, care coordinator, peer support specialist, \\
Miles City & Care coordinator, MH NP & 2 \\
Polson & LAC, prescribing provider, RN care coordinator, RN & 4 \\
Hamilton & Care coordinator, prescribing provider, BH specialist & 3 \\
Missoula & LAC, prescribing provider, RN care coordinator, CEO & 4 \\
Total & Care coordinator, prescribing provider & 2 \\
\hline
\end{tabular}

${ }^{1}$ Medication Assisted Treatment Registered Nurse (MAT RN), Behavioral Health (BH), Corporate Executive Officer (CEO), Nurse Practitioner (NP), Licensed Addiction Counselor (LAC), Chief Marketing Officer (CMO), Chief Operating Officer (COO), Mental Health (MH) 


\section{SECTION II: RESULTS}

\section{Developing an OUD}

Many of the patients who participated in this study reported an early introduction to drug use as adolescents or teenagers, and MAT program staff face many challenges in supporting a change to their life trajectories. One patient from Big Horn stated, "I thought it was only like three years that I was on opiates, come to find out I've been on them for 13 years."

Most patients reported a long history of opioid abuse before seeking treatment. Others were introduced to opioids later in life after an injury or as treatment for chronic pain. Regardless of how long they suffered from addiction, when asked what their day-to-day lives were like before treatment, many patients expressed regret and told stories of "the chase" or "the hunt." One patient from Big Horn stated: "All I thought of was where my next pill was going to come from. I mean, I didn't think of anything besides the next time I was going to get high. I'd be thinking about the next time while I was doing it." Other patients discussed how searching for and affording opioids occupied most days. Paying for opioids forced patients to make some difficult decisions. We spoke with one patient who pawned his prized horses, several horse trailers, and a pickup truck to buy pills. This was not an uncommon story across the state. One patient from Bullhook described the sacrifices he made to afford opioids:

I'd sell my boat, I'd sell my tackle boxes, I've had nice rods and I'd sell them, I'd have nice reels, I'd sell them. Anything I could do for money. And now I've had the same rod and reel since forever, and tackle. I had this little 14-foot boat and a motor that I sold, and that was all to just get dope or drugs (Bullhook patient).

Patients described addiction as all-encompassing and shared the ways in which their efforts to gain access to opioids became a central driver in their lives. Some patients said it was not about getting high but about a search for opioids to "maintain" their physical welfare. One patient from Bullhook shared an emotional story about prioritizing her addiction over her family:

It was actually Christmas. This is one story that I still have to heal from the decisions I chose to make here, but it was Christmas and I was searching, searching, searching for something. I didn't want to feel crappy when we were opening presents. Like 15 minutes before we were going to open and I just disappeared. My family's looking for me, my husband's looking for me [...] but it took time away from us opening presents to look for me because I just disappeared. [.. .] I found what I needed and we got back and I opened presents. Then, I had like a dull mood all throughout the day. Then, I got back and had my stuff, and then I was like high, high energy. It was almost through the roof. You just couldn't imagine. Everybody knew something was up. My mother-in-law actually approached me and asked me, "[Patient's name], we know you're high, and we're going to ask you to leave because we don't want you around the kids, and we don't want you here while you're high" (Bullhook patient).

Patients spoke about alienating themselves from their families and losing respect from family members because of their drug use. One patient from Butte described how addiction altered her relationship with her children:

But my kids, we've finally reversed roles to where I'm the parent again and they're the children, where before we kind of shared that role, depending on the situation.

[Interviewer] Do you have any stories about that? 
Well, in my addiction, it was more like a team effort to just survive, I guess you'd say. Then when I got sober, they were very wary of leaving me alone, letting me go do my own thing. They would check on me most of the time, and they didn't leave me alone. I had to bring them with me wherever I went because they didn't trust me because I lied so many times about being sober when I really wasn't. Then, after a while, it took a couple months to where they were a little more lenient and they'd let me go alone. Now that they see that I was serious about it and I meant it. Well, now I'm the parent and they can finally be the child again (Butte patient).

Addiction permeated the lives of patients and their families. Before entering treatment, patients told us about the ways in which they prioritized the 'chase' over opening Christmas presents with their children and instead of tending to their children's day-to-day needs. In addition to focusing on drugs more than their families, patients would pawn their possessions to afford their drug of choice.

In the context of addiction, it can be difficult to initiate treatment as a pathway for change. The fundamental goal of the SOR MOUD site evaluations is to identify how the expansion of MOUD treatment through SOR funding has assisted individuals who seek to overcome the challenge of addiction and pursue a different life path.

\section{Continuing or Improving Health Benefits and Outcomes for Patients}

One of the fundamental goals of a health program is ensuring that patients receive highquality care that promotes the desired outcomes. In MAT sites the desired outcomes are varied, with a shared goal of supporting patients in their own individual pursuit of recovery from OUD. This section provides insights from both provider and patient interviews about how well MAT sites are meeting their goal of continuing or improving the health benefits and outcomes for patients.

\section{Substance use outcomes}

Sites were asked to provide perspective on the types of patients that do well within their MAT programs, as well as the types of patients that do not do well within their programs. Success within the MAT programs was defined as a patient who reliably arrives at appointments, follows dosage guidance for the medication, considers or engages with behavioral health supports, and begins to experience positive shifts in their social and medical conditions. Positive shifts in social conditions are patient specific; site staff mentioned outcomes ranging from exit from an emotionally abusive relationship to healthy pregnancies, steady employment, and use of health services. Consistently across sites, we heard of efforts by staff to work with patients to develop individualized definitions of success that aligned with clinical standards and guidelines. One universal goal was to ensure that clients decreased their use of illicit opioids. Sites monitored this outcome with Urine Analysis (UA) screenings as well as direct conversations with patients.

\section{Patients' perspectives on success}

The act of entering treatment was a marker of success for many patients, and a monumental change in their lives. One patient in Big Horn stated, "I wouldn't be alive today if I hadn't gotten in the program." Across sites, patients echoed the theme of being "given a new chance at life" or being "reborn." Another patient from Big Horn stated:

I felt like a brand-new person. Like I just got immortalized, like everything from my aches and pains, I just felt like a brand-new person. I just became reborn again. [. . . I I don't even want to look back on it. I'm just blessed that there's 
actually a program that can change my life, and be a better person, and be a better mother and wife, for my kids, my husband (Big Horn patient).

When asked "So, for you, what are some of the primary benefits of participating in the MAT program?" one patient in Polson responded:

I'm here with my kids. I'm present in their lives and not out spending money on drugs that I could be using on bills or stuff for my kids. I'm here mentally. I know some people feel some way about Suboxone, but if it wasn't for Suboxone, I'd be spending unnecessary money, and I wouldn't be here mentally because I'd be always out trying to find my next fix (Polson patient).

Patients stated that MAT helped them to get their lives back and avoid the "chase" and enabled them to become better parents and partners. The MAT program helped them shift their priority from drugs to their interpersonal relationships. In addition, patients stated they were able to resume their daily hobbies and pursue their passions. The patient from Bullhook quoted earlier as having sold his fishing equipment to afford opioids stated:

I have money, I just bought a thousand-dollar boat. Let's say before I got on [MAT program] all that money would've been gone to drugs. All of it. But since I've been on it, I also just bought myself a new bow. The bow I've always wanted actually, ever since I started bow hunting, I always wanted a Bowtech, but never could afford one (Bullhook patient).

In addition to repairing relationships with friends and family, this patient credited MAT with his renewed interest in the outdoors and his material ability to pursue these interests. In contrast, the "chase" inhibited people's relationships but also interfered with their recreational pursuits. Before treatment, patients abandoned their passions and exchanged recreational gear with financial value for money to acquire opioids.

Patients enrolled in Montana's MAT programs generally reported positive outcomes from taking Suboxone to reduce withdrawals and relapses with illicit drugs. All patients expressed gratitude for the programs and wanted to ensure that they continued. One patient from Big Horn stated:

Keep this program going. Honestly it should. It should be there $100 \%$ times 10 for the people like me, for my friends. I told all my friends, be on this program. Honestly, you'll be so blessed. I said, "I want to live a long life. I'm sure you do." And I have a couple people that are cancer patients that are on opiates, and one of them, she actually beat her cancer. She's cancer-free, but she's still taking opiates. And I'm like, "Gosh." I'm trying to fight her through with this (Big Horn patient).

This patient credited her successful recovery to the MAT program and Suboxone. She also described additional demand within the community and noted that the MAT program could be valuable to others who have yet to enroll.

Other patients discussed the value of the MAT program. A patient from Butte stated: "The biggest thing for me was this is the first and longest time that I've been able to stay sober in my entire life-one year doesn't seem like a lot, but to me it's huge." Patients expressed support for the MAT strategy and credited medications and staff support for their sobriety. A patient in Hamilton stated: "I kind of look at Suboxone as the same way as I look at my antidepressant. It's just something I need in a balance." Another patient in Bullhook described it in similar terms: "Diabetics have medication so that they're better. They have to use their medication. That's how I feel like this is: we have medication for a different disease, and we have to use it in order to get better." Patients commonly viewed Suboxone as a medication rather than an illicit substance-"one drug for a different drug." Some patients described their 
perspective on Suboxone and its impacts for success in more detail. One patient in Butte explained:

Okay. I would say it's not a drug. It's more like a stepping stool, like a crutch, that you can use, so that you can go to work and do stuff at first. You can get away from all kinds of people, so you can get out of that scene because you already have that part that makes your brain and body okay. You don't have to go and look for that, you already have it. So you can spend your time, instead of looking for drugs and spending all your money on drugs, you can go out to eat and do normal things. You're not high, so it doesn't seem unreachable or you're so high you're uncomfortable. It's just a maintenance where it's already there, you don't have to continually think about using drugs and getting drugs every day (Butte patient).

The MAT program provides patients with an opportunity to reduce their withdrawal symptoms and recover while they accomplish life's daily tasks. Patients described being able to work, be social, participate in their best-loved activities and be more involved in their children's lives, all while remaining sober and present. Patients described having a better understanding of addiction and treating it like any other disease: with medication.

\section{Providers' perspective on success}

All providers expressed a positive perception of the MAT program and the beneficial role it can play in the lives of patients, although there was some variation in how effusively they spoke about its potentially life-altering effects. Success within the MAT programs was defined as a patient who reliably arrives at appointments, follows dosage guidance for the medication, considers or engages with behavioral health supports, and begins to experience positive shifts in their social and medical conditions. Positive changes in social conditions are patient specific; site staff mentioned outcomes ranging from exits from emotionally abusive relationships to intentional pregnancies, steady employment, and use of health services.

Across sites, we consistently heard about staff's efforts to work with patients to develop individualized definitions of success that aligned with clinical standards and guidelines. Many participants pointed out that success was often related to the time from when patients presented and the "time to induction". A Kalispell care coordinator noted, "You know, they can't wait three months for something like that [induction]. It's a pretty urgent thing. [...] If you can't get them in within a week, most of them are probably going to use again." When programs are able to respond to potential patients within the timeline for success and patients enter the programs, many providers had a positive perception of the MAT program and its beneficial, life-altering effects.

I started providing this medicine four years ago. I was like, someone's got to do it. I went into it reluctantly, and then once I started, once you start working with people you develop relationships, you develop the trust, you get them following a program and you get them working through, and to see them succeed is incredible. And when you look at data, with the right support and the right backup, and they're still doing it themselves, we're just here to help guide them and be an honest sounding board. And then, when you see the results, you can get results better than diabetes if you do this right, if you do this well, with proper monitoring, nonjudgmental attitude toward their behaviors, treating it like a disease, taking out the stigma from it and just saying, hey, let's work on this together. Your goals and our goals are in line. You're going to slip up a little bit. We're not going to fire you, we're just going to keep working with you, so seeing success from individuals. I've been doing family medicine for over 25 years, and when you can work with someone in their 20s and 30s and change their life trajectory, that's huge. [...] I mean, that's powerful stuff so just seeing 
how... The medicine, I look at it, is just stabilizing, it's all it does. It keeps them stable, and then we start working on the other things that will give them control, get them recovering in life and get them going in another direction. No, I can't ask to be doing a better thing with my career (Missoula medical director).

The positive effects MAT programs go beyond their impacts on patients: this participant conveys a high degree of satisfaction with providing care and helping people change their lives for the better. This marks a shift in how staff described their level of expertise and comfort during the STR grant program evaluation. It also demonstrates how staff find meaning by providing care through the MAT program.

Site staff also talked about how success goes beyond merely continuation with the program. Multiple interviewees expressed a desire to be able to track and quantify what success actually looks like in everyday life. One waivered provider in Polson said:

Other things that we've thought about, we at different times have a discussion about, what does success really look like? Do they have a job in the end? What is being a productive member of society? What are some things that could be some check boxes of that? So we've thought about it, but we're not necessarily formally doing an eval, I guess I would say. I think a tool would be awesome (Polson medical provider).

In this context, success is defined as continued engagement in the program and the accomplishment of patient-directed goals that improve patients' life circumstances. When considering how sites have been able to continue or improve these outcomes, staff discussed the ways in which additional experience has increased their expertise at delivering care and thereby resulted in better outcomes for patients.

Other participants noted that as they gained more experience and familiarity with addiction, their views toward harm reduction shifted. For instance, one participant commented:

So we're focusing on keeping people in the program, even when they're struggling and not necessarily meeting what we think are our expectations, in the hope that even though they're not using and they're blowing off some of the other things that would benefit their life, in the hope that they will eventually see the value of doing more (Missoula coordinator).

The Missoula coordinator described weighing her own beliefs about patient abstinence versus the harm reduction approach espoused by MAT programs. Initially, she believed patients should adhere better to the program's policies when they started treatment; with experience, however, her perspective changed, and now she hopes patients gradually become more adherent as they progress through recovery. A MAT program's observance of harm reduction instead of a focus on abstinence signifies a shift toward an empathetic view of addressing addiction and increases capacity to tailor the program to individual patients' needs and goals.

\section{Health outcomes}

One major benefit reported by providers is that patients who participate in the program begin to access dental, general health care and treatment services. This was a consistent message among Blackfoot program staff, as these two participants noted:

It's nice to watch patients that are doing well use this as a pathway to do better and their overall health too. We see a lot of patients, once they start to have success with the Suboxone, start to participate in more health maintenance, preventative services, as well as address other health issues that have maybe been on the back burner when they've been in the depths of their addiction, I 
guess. I think that we've seen a few patients not only getting clean but they're getting healthier too (Blackfoot LAC).

And part of their care plan too, what I really feel is important is I always make sure their medical needs are taken care of, because of their opioid use, a lot of them have really bad teeth. So I'll get him set up for dental, get them set up for a basic medical exam, get them set up for dental, eye and that's about it. And then if they're diabetic, I make sure I try to get them in with a provider that serves diabetic clients (Blackfoot CEO).

These staff members contended that once patients gain access to treatment, they begin to prioritize their health and well-being. By addressing their full range of health concerns, they stabilize their recovery goals and increase MAT program retention.

Staff across multiple sites mentioned the value of the integrated model for broader health concerns. In Bullhook the CEO stated:
I think getting all their care in one spot and that it's not hard to get here. We're centrally located here in the community. There's so many different people they can talk to, whether it be a care manager, they can talk to their nurse, they can talk to their provider. The communication is not hard. And also, Brandn, when we were talking about the clients that we get that are also involved in drug court. Actually sitting down and talking to them and seeing what their schedule is in a day, it's a lot, especially after they've been used to coming and going as they pleased and not really being accountable, and so you think, "Okay, so I have to see my parole officer in the morning, and then I come to Bullhook for group, and then I need to come in and see my provider for the Suboxone," and things like that, so they really have to step up (Bullhook CEO).

The integrated model promotes recovery as a lifestyle, thereby shaping patients' daily lives. IMAT staff, like this Helena LAC, describe the struggles associated with improving diet and exercise which contribute to patients' healthy lifestyles: "I'm also in recovery, too. [. . .] Exercise is a big part of my recovery. So I try to encourage it whenever I can. I feel like it's so beneficial to recovery, but a lot of people ... There's just this barrier to exercise and gyms." This participant described patients' resistance to exercise and a healthy lifestyle alongside MAT treatment. Other staff, however, described several healthy lifestyle improvements. For instance, this Bullhook behavioral health manager stated:

The patients that come in, they haven't taken care of themselves very well, and their medical is suffering, or their teeth have been neglected for years due to drug use or just their inability to pay. We're fortunately in an FQHC, we have care managers on staff that help patients get on the Medicaid's sliding fee scale, payment plans, whatever it may be, we're at an advantage because of that, but we've had patients here come in with mouths full of abscess and decay, and that same day we're like, "We need to get you up to dental today." For something they've been avoiding for so long, they're able to have less anxiety and fear about going, because it's just "Oh, I'm here, right here." We can take care of it. It's been beneficial (Bullhook BH manager).

Some participants described a shift among patients to a healthier lifestyle. Once patients become familiar with and comfortable in the clinic and around its workers, they are more willing to treat other neglected healthcare concerns. In addition, the Bullhook BH manager described another benefit of the patients' trust in the mental and physical healthcare offered at SOR MAT clinics: "Some of the clients have young kids, and I notice that they've been starting to bring them in for a young child immunization and earache, sore throat, things like that, and so it's a win-win, because they feel comfortable here." Staff reported that although ensuring that patients and their families address pressing health concerns is an ongoing challenge, 
progress in this area could potentially create a health-centered precedent with multigenerational impacts.

\section{Providing care to special populations}

\section{Working with criminal justice-involved patients}

Staff from Montana's SOR MAT sites described working with patients involved with some level of the criminal justice system: currently incarcerated, on parole, or with a history of incarceration. Some staff described these patients as very compliant, whereas others described the challenges of working with this population. For instance, a Blackfeet care manager states: "Yeah. I actually have one client who had just recently come out of prison and he's on probation. He's very, very compliant." Staff at several other sites recounted more experience working with patients on parole. The Helena BH director stated:

I don't have an exact number for you, Brandn, but it really wouldn't surprise me if $50 \%$ of our MAT participants are on some sort of supervision. That's totally a rough estimate, but yeah. That's a pretty big overlap for our MAT program (Helena BH director).

A Miles City staff member noted:

We do have a really good communication with probation and parole here. They do a lot of referrals for their inmates and stuff coming out of pre-release and needing to get some extra support. So they've actually been really good (Miles City MAT team member).

By managing patients' medications and providing behavioral healthcare services, staff strive to make recovery an active part of keeping patients out of jail in the future. Some staff understand their limitations and the opportunities for future growth within the justice system. A Butte executive stated: "The largest area for us is still in the justice system. Whether it's dealing with drug courts, or those people that might be incarcerated and already on treatment [...] that's an area that we have a lot of room to grow."

The collaborations between MAT site staff and criminal justice staff referrals serve to enable or constrain the treatment that prospective patients involved in the criminal justice system receive. It can be challenging to deliver the integrated model of care in the MAT program to criminal justice-involved patients, as being incarcerated or on parole can make it difficult to meet the demands of 'the program and their court order.

\section{Polysubstance use}

Staff at SOR sites shared observations about the challenges that can arise from patients' polysubstance use. In contrast to the observations shared during STR, site staff reported becoming more open and accepting of polysubstance use in MAT clients. This openness was generally concentrated on clients using alcohol and marijuana, while some concern about methamphetamine use remained.

One behavioral healthcare director in Helena commented: "In terms of people who come into our clinic, when their primary drug of choice is stimulants or methamphetamines, that's kind of a target area we all are looking to get more training in." The lack of expertise on methamphetamines may lead MAT program staff to question their approach to harm reduction and the goal of their recovery programs. An LAC at the Blackfeet site said: "I think what [patients] don't understand is [...] people in our community had started using Suboxone before they started using meth. They were getting the pills before people started selling them meth here." In other words, people were in recovery for their opioid addiction, and then 
began to use meth. This sequence of events and the lack of treatment options for addiction to stimulants can magnify the risk associated with opioid addiction that was previously being effectively managed.

SOR sites have also observed successful management of polysubstance use, as stability brought about by participation in the MAT program can empower patients to stabilize and

self-manage abstaining from methamphetamine. This Butte provider commented:

So our clinic, our program, we make it very clear that Suboxone is to treat opioid use disorder. That we find a lot of people as they are able to get off opioids, that the meth use falls away naturally as their life comes back together (Butte provider).

The harm reduction model may not reduce short-term polysubstance use, but it may contribute to long-term cessation once patients begin to experience the widespread benefits of MAT. A member of the Big Horn Care team commented on the need to promote harm reduction versus total abstinence when it comes to methamphetamine: "To best support MAT patients in the program so that we're not looking automatically at discharge, we're making sure we have all those barriers down and can ultimately support them." Staff from SOR sites noted that requiring patients to be abstinent from all substances hinders the likelihood of positive, long-term life outcomes. Considering each patient's life history and pattern of drug use, SOR staff aim to promote long-term recovery, in contrast to an abstinence model that they suspect leads to short-term gains and a higher incidence of relapse.

MAT staff face several persistent challenges among a population of patients with polysubstance use disorder. The harm reduction model enables patients to continue to use illicit drugs, which may negatively affect their overall health outcomes. Rather than fully committing to a healthy lifestyle, many patients continue their drug use. As one Hardin executive stated, "All of our patients who are using substances are polysubstance users. And so meth has been a scourge here for a real long time, and it waxes and wanes." By joining the MAT program, some patients tackle one threatening health issue, while neglecting and even perpetuating others.

\title{
Chronic pain
}

Providers verified that many of their patients initially sought opioids to relieve chronic pain and became addicted to those medications. An executive in Butte stated:

\begin{abstract}
Many people that slide into buying pills or heroin from the streets started with chronic pain issues and just split downward. For many, many people it's so intricately woven together. I think absolute chronic pain and getting people on the right medications for their chronic pain. One great benefit we offer is that we get them in with a primary care person. I should have mentioned that earlier actually. So we do the MAT program, but then we also get them to see a primary care provider (Butte CEO).
\end{abstract}

This participant described how patients often start off innocently enough: taking medication for pain and then developing a dependence on their prescribed dosage, abusing their medication, or switching to illicit sources to fulfill their addiction. In addition to MAT, this participant described how engaging patients with a primary care physician can help them obtain the proper pain medications and dosages. By empowering patients to work with MAT staff and pain specialists, MAT programs enable patients to better manage their pain, wean themselves off of pain medication, and hopefully avoid additional adverse effects of addiction, such as overdose. 
Other staff warned of the dangers some physicians and specialists pose to the recovery of MAT patients. Knowing that a patient suffers from chronic pain, a physician may prioritize a patient's chronic pain management and overlook the risk of dependence, thereby undermining the patient's recovery and dismissing the relevance of MAT. This MAT RN stated:

If you have a provider that's actively providing an opioid for a chronic pain patient and won't push that patient off to a pain clinic, say, why would they want to go on the MAT program? The provider is telling them that they need the medication and actively prescribing the medication, so that's the barrier (Ashland MAT RN).

In this case, participants described how physicians may legitimize a patient's (mis)use of pain medication, further exacerbating their addiction. Without a mandate on whether pain patients address their opioid dependence, some patients' addiction may persist with the endorsement of physicians unable or unwilling to diagnose their addiction. The nurse from Butte said that more education is needed among physicians, and among pain patients themselves, to address the issues that follow from overlooking opioid dependence and the need to engage pain patients with behavioral healthcare workers.

When providers legitimize the use of pain medications, they perpetuate the perception that chronic pain patients are not addicted to their medication. A Helena LAC commented, "But I don't see a lot of chronic pain people because, when they show up, they say, 'I'm not an addict. I'm not an addict. I'm just in pain and I need medication." A Missoula coordinator confirmed, "A lot of them have difficulty actually accepting themselves as addicts. And we're not going to push them on to say, 'I'm an addict' or any of that stuff."

Staff in this study described the difficulty many chronic pain patients have admitting to themselves and to their providers that they suffer from a dependence on their pain medication. The Missoula coordinator described treating these patients differently from other addicted populations, as if they are not "real addicts." The peer supporter confirmed that this perception and treatment change the behavior and recovery trajectory for these patients, who are permitted to be less engaged with the MAT program's psychosocial resources and requirements. The Helena behavioral health director underscored why this pattern exists: "A lot of our chronic pain patients just have more of that long-term remission, and don't require the same level of services." Chronic pain may require a lower level of care, or as the Polson program manager stated: "I think Maria said that chronic pain isn't covered as a code under insurance for them to use Suboxone." Thus, insurance may serve as a structural barrier to integrating patients into a recovery regime that treats both pain and addiction.

\section{Patients' perspectives on chronic pain}

About half of the MAT patients interviewed for this project stated that their addiction began when a doctor prescribed them opioids for chronic or acute pain, which later led to drugseeking behavior. One patient from Bullhook who had had a preexisting opioid addiction described receiving a script for a large dose of oxycodone, which she began overtaking:

I had a C-section with my daughter, she'll be four in September. So of course, I was prescribed oxycodone. And I mean that doctor was giving me quite a bit. He was giving me like 30 every seven days, so I got addicted pretty quick, again. Like I made it worse I should say. And so that's where I got worse into the oxycodone. That was like an everyday thing for like two years, three years.

Several patients noted described that addiction originated when they started overtaking their pain medication. Other patients recounted their process for obtaining medication for illicit use in more detail. A patient in Butte commented: 
Then I would doctor shop. When I got older, I had cancer, and it was right when Oxycontins were just coming out as a miracle drug or whatever. So I got a prescription of 90 Oxy 60s a month and 120 Oxy 15s. While I was battling cancer. Then it just went from there. I was 21 when my opioid addiction really, really took off. Then I was introduced to heroin when I was 30.

\section{[Interviewer] Why the switch to heroin?}

It's cheaper (Butte patient).

Participants described an increase in use upon receiving medication for pain and a transition into illicit use of medication that later evolved into intravenous heroin use. Many patients also explained the moment they knew they had a problem with their medication. One patient in Missoula reflected:

I knew I had a problem when one day I was watching TV and there was this woman pushing her little kid on a bike. I thought to myself, "Oh, I could do that, but I'd have to have pain pills to do it." That's when it really hit me. [...] Because my whole day was around pain pills. I couldn't function without them. I was in too much pain if I didn't have them and [. . . Because I have a chronic pain disorder from a car wreck that I had. It gave me the energy to get going and just the motivation to do stuff (Missoula patient).

This patient's recognition that she was unable to function or live her life-to carry out simple, everyday parenting responsibilities, like helping her child ride a bike-without pain relievers inspired her to seek help and begin her recovery through the MAT program.

Other patients described having a preexisting addiction before a doctor prescribed an opioid pain reliever. Another Butte patient reported battling a heroin addiction for years, well before a dentist prescribed him oxycodone. Here is that exchange:

[Interviewer] So, wait, the dentist prescribed you opiates?

Yeah.

[Interviewer] Really? Did they not know that you had shot heroin before?

I never really talked to anybody about that (Butte patient).

Ultimately, if patients do not disclose their risk of misuse of prescriptions, doctors may prescribe medications that cause them to relapse. This patient stated that the dentist visit started another long, active battle with addiction that led him to the MAT program in Butte.

One patient, watching her friend face criminal charges for meth and facing the threat of criminal prosecution for her own addiction, saw her own drug use and addiction in a new way. She began to understand that it was her addiction rather than the pain that drove her use. Other patients described their exhaustion with the criminal lifestyle as motivation to seek treatment. Still others described horrific accidents leading to change. One patient from Big Horn recounted being the passenger in a vehicle with an intoxicated driver. When the car crashed he had not been actively using, but he broke a femur, and this experience convinced him it was time for a change.

Many patients described being wary of pain medication, even over-the-counter pain relievers. One patient in Hamilton stated: 
All I know is: I'll never touch another pain pill in my life, which everybody's told me getting off the Suboxone, you go through a detox. I don't really focus on that because all I know is I wanted to be off the pills, I just didn't know how to get off of them. And now that I haven't done a pill, I will never touch another pain pill ever. I will deal with pain versus taking the easy way out, I guess (Hamilton patient).

This patient explained that she will never take ibuprofen, acetaminophen, or NSAIDs owing to the risk of forming a new habit. To the question "You don't take anything?" she replied, "Nope, I just suck it up." Many patients hesitate to take pain medications for fear they will revert to taking opioids. Other patients manage pain through several methods. One Big Horn patient explained: "I'm doing physical therapy. [. . .] Motrin and Tylenol. That's about it."

For many patients entering the MAT program was a paradigm shift through which they sought and received healthcare for ailments that had gone undiagnosed and unaddressed for years. When the participant above began her recovery, she changed her entire lifestyle: she began to exercise more, changed her diet, and began managing pain with over-the-counter medications rather than prescription opioids. Several other participants reported that physical therapy was a major component in their pain management regime. Other patients provided a little more color when describing their approach to pain management. A patient in Butte stated: "I smoke lots of weed. [. . . I take it easy. I try to just burrow through it. You know what I mean? Because the Suboxone and stuff, that doesn't really take the pain away. [. . .] About half and ounce a week." The harm reduction model enables this participant to recover from his opioid addiction while using THC to alleviate his pain. He describes the staff as being supportive of his pain mitigation strategy, and their attitude toward his THC use encourages him to stick with the MAT program.

\section{Program retention and reenrollment}

A primary goal of each site is to retain patients in the MAT program. The first challenge occurs in the first few weeks after a patient enters the program:

Yeah. Yeah, definitely. What I've seen is individuals that participate in the MAT Program, there's this transition period, maybe the first few weeks to like the first two to six weeks, where they may not be engaging in any type of additional services directly, and then after that period they begin to engage with peer support and their addiction counselor, and then it seems most people are really successful on our MAT program. I usually will continue to visit with them for eight months to a year, and then I'm available to them after that, but we don't necessarily have scheduled visits (Helena peer support specialist).

I also think that it also has made, for the mental health therapy component, that referral and that transition is a little bit easier when they start down in behavioral health. Not that we don't get referrals from medical, but it's just an easier connection and we see less resistance from patients that really do need that mental health therapy (Bullhook CEO).

The Helena peer support specialist described the first few weeks as a critical time to reengage with patients as they initiate services and begin recovery. In addition to the challenges staff face retaining patients initially, a nurse in Butte described how some patients are deterred by the length of treatment and the reality that the recovery arc will remain with them their entire lives.

The behavioral health and counseling portion of the program aims to tackle the antecedents of addiction: the complicated backgrounds and life histories leading to addiction. However, a few staff said that accountability may serve as a barrier to potential patients looking to 
enter the program, as one's readiness to be held accountable for actively pursuing recovery can affect one's ability to engage in the recovery process. As one prescriber remembered:

I'm thinking of one gentleman specifically. Is like where he specifically, I don't think he was in a place where he actually wanted to change and stop using. But his parents were waking him up out of bed and taking him to the appointments, and they sat in on the appointments. They desperately wanted him to change, and of course, it's their son and they want him to be happy and healthy. The way he was going was in another direction. I get where they were really trying to make it better for him. But when it's the family dragging the person along and the person's not in the space to do it, eventually the person is going to win. They're going to try to stop coming, and I think that's what we see pretty often (Butte prescriber).

A Blackfeet care manager noted:

So she goes to the behavioral health specialist who picks her up by the hand and walks her through everything, and she loves that. But I don't do that. So she avoids me. And my job is to build a nice healthy relationship with my clients to support them. That's my goal is to be there and help them. I love to see success, but they're always going to fall and pick back up. And so just that is probably the only one that I've ever had that was unsuccessful case because she's not ready to do what is going to help her (Blackfeet care manager).

As these quotations describe, the prospective patients were not ready to change and pursue recovery. For the patient in the first quote, still in the grips of addiction and unwilling to change despite his parent's best efforts, compulsory engagement with treatment served as a barrier to retention. The patient described in the second quote was unable to be accountable to the program's requirements and not ready to actively pursue recovery.

\section{Patients' views on retention and reenrollment}

Patients describe a positive treatment atmosphere and helpful staff at the onset of their admission and throughout their recovery. One Hamilton patient described her experience starting the program:

It actually was a pretty simple process, and when I left, I just really felt good about myself. They were welcoming, "Glad that you're here," and just really encouraging, really encouraging. Helpful. The therapist, I think addiction counselor lady I work with, she's really cool. Even the front desk ladies-they just have a really good crew in there right now, and I think they're awesome. So between the mental health and addiction, it's a very helpful place (Hamilton patient).

Patients express gratitude for the care, attention and respect MAT staff show them. Patients describe being vulnerable when starting treatment and progressing through recovery. A Polson patient reflected: "Caring, how they care. I don't know. We're not just a prescription to them or something. They care about how we're doing, and they want us to do well and they're always checking on us." This patient said that when staff demonstrate an attention to detail and attend to each patient's treatment goals, it encourages them to stick with the program. Because she receives calls from staff to monitor her progress, this patient feels accountable to the program's rules. This respect bolsters trust and encourages patients to remain in the program.

This Bullhook patient commented on how the trust and respect he receives from staff compels him to remain in recovery: "So, I'll do anything that I have to do because my life right now is a 100 times better than it was. Heck, a million times better than it was before." Patients reap positive results not only from the relationships they forge with program staff but also 
from the medication. Seeing positive results gives them the confidence to pursue their recovery goals and remain in treatment. Sometimes, however, the insidiousness of addiction overwhelms the hard work of staff and patients. One Bullhook patient commented on her reentry after a series of relapses that got her kicked out of the program:

See, my first time on the program it was [nurse] and then she was really nice to me, but I kept messing up, and so she had to let me go, and so I [kept relapsing and got kicked out of the program]. Yeah.[. . . I was pretty mad about it, but I guess it was my fault because I kept going in there with dirty UAs. [. . . I I felt welcome because I guess [nurse] was saying that she was bugging the board to let me back on. So I felt pretty welcomed with her (Bullhook patient).

This patient had several relapses with opioids and other substances, which inhibited her ability to follow the program's rules. Initially she was upset about being expelled from the program but later realized it was not the staff's fault that she perpetually violated the program's policies. She reentered the program eighteen months after her removal; and described a welcoming environment and noted that staff had advocated for her readmission.

\section{Barriers to successful outcomes in MAT programs}

\section{Lack of transportation}

Montana's frontier landscape presents challenges for staff seeking to personalize the program and for rural patients with few resources to transcend geographic barriers. For many patients, transportation to and from appointments is a major barrier to continued engagement with the program, and staff are always working with patients to resolve this issue.

What I see most with our Browning population is their commute to Kalispell, which is over an hour and it's through a pass. And the medication and the services that we have been providing with the folks over there, I have seen to be effective. But the main barrier as with all barriers in healthcare is transportation. And that a lot has to deal with, they rely on the public transportation. There's this bus that comes (Blackfeet RN).

Most of the time the people who want to transfer to us are ones that Ideal Options are struggling with, not because they're not doing well in the program, but because transportation is a big issue for them. Ideal Options is in Great Falls, yes. And I would say it's quite a few Native Americans who started out there because we didn't have room in our program and nobody else around here was doing it at the time. So that's where they went. But a lot of them were provided transportation by the reservations. And then when COVID started, transportation became non-existent (Bullhook care team member).

Public and private transportation options throughout rural Montana are often unreliable, or inconvenient at best. As more MAT clinics are located throughout the state, such as the newly opened program in Glendive, patients can reduce their travel time and seek treatment in more convenient locations.

Yeah, one time I went [to Great Falls], and it was like 60 below with the wind chill. Yeah, it was cold. It was very cold. Yeah. I stuck to it pretty good. I made sure I was up because it's the transit that comes from Fort Belknap that only goes to Great Falls on Tuesdays and Thursdays, and I had to explain that to the doctors, and so they were okay with that. And I would wear my coveralls, I'd have hand and feet warmers. I'd have my lunch, I'd have a Carhartt coat, gloves, hat (Bullhook patient) 
This patient eventually transferred to the MAT program in Bullhook because it was more convenient than taking a bus to Great Falls from Havre, especially in conditions of $-60^{\circ}$ with the wind chill. Staff and patients described transportation as a prohibitive factor, and mitigating this challenge increases a patient's likelihood of retention.

\title{
Challenging social conditions
}

Additional challenges to retention come from outside the program context. Providers mentioned patient's' social conditions and background, unstable housing situation or lack of recovery housing, co-occurring disorders, and social relationships. Patients' background and social conditions may adversely affect their engagement with the treatment program. Several staff commented on the broader structural forces facing patients' life chances:

\begin{abstract}
You know, people might do well for a little bit, but then they don't have a car or they can't get to an appointment or they don't have money for whatever. They're homeless, so they're staying with a friend over here, and then usually those kinds of people, a lot of them are still using. So then they get sucked back into it. [... . So I think it's the people that don't have all of that structure in place, it's so easy for them to just fall back in with the wrong people or not have the transportation or the resources to get to the appointments or pick up their prescription or keep their Medicaid active. So they don't get their mail. So then their Medicaid goes inactive (Kalispell care coordinator).
\end{abstract}

Oh, that's been a challenge as well because a majority of the clients don't have internet. They don't even have access to a computer or a laptop, maybe an iPad. Not all of them have a cell phone, and if they do, a lot of times they don't have minutes. They'll have a non-working number. I found that yesterday I reached out to some of the clients and probably I bet 6 out of 10 phone calls of the clients that I contacted no longer had a working number. And with what's going on, we just have to keep trying and hopefully they'll get minutes. I don't know, but I won't go out and find them. I can't do that (Blackfeet care manager).

Unstable employment, insecure housing, and a lack of resources, such as money and reliable means of communication, force patients to prioritize a long list of needs before their treatment. These structural disadvantages accumulate and often lead people to drop out of the program. Furthermore, as the Kalispell care coordinator notes, many people have social relationships that promote relapse. A Blackfeet RN stated:
And he did tell me that there was some things going on in his personal life because he was trying to get his stuff together, but then he had a partner that was still using. [...] I guess, I'll tell you the ones where I see that it's more challenging for them to participate in the program is when they're with a partner who does not want to stop using. Those are the main people that I see where they're not successful in the program, is when they have that person where they're in and out of the clinic. Sometimes they come, sometimes they don't, they're missing days. They're not fully invested in the sobriety, because they have that other partner that is just not willing to quit. The only thing I can think of like as an analogy is of the domestically abused person, where it's just so hard to get out of that relationship (Blackfeet RN).

For several patients the lack of mental health care coupled with continued engagement in social relationships that promote illicit drug use led to relapse and violation of the program's guidelines. Staff reported frustration with the housing options available for patients seeking treatment for substance use disorder. And the Missoula medical director commented: "The other population that's really tough are those with unstable home life, that are couch surfing from place to place, and having some stability in their life and so trying to keep track of them as they're moving." The lack of intermediary sober housing options below an in-patient 
treatment designation concerned staff. They described one's living environment as a trigger for relapse and emphasized the need to mitigate housing as a social determinant of poor health outcomes and a strain on recovery.

\section{Lack of treatment capacity and access}

According to patients from across Montana, gaining access to treatment continues be difficult owing to a lack of providers, staff and clinics-a situation that contributes to their continued addiction and stymies their recovery. One patient in Butte said: "I think there should be more places to help. Yeah, I would definitely put up more places like the clinic or the SMART program." This patient recounted her own experience looking for help and struggling to locate an addiction program. Other patients expressed similar thoughts:

So, I mean, finding help was honestly the hardest part, but then I ended up hearing third party about Turning Point, and I just walked in one day. But yeah, trying to call the $\mathbf{8 0 0}$ numbers and all that, literally, I mean it's harder to go through that than it is to get off drugs. You're better off just going and getting high. They make it so difficult, and they are so scripted in what they say, that you know what I mean, you don't feel like anyone cares. It's someone at a call center that, you know what I mean, is just trying to get insurance information so that they get paid (Missoula patient).

This quote also touches on a related theme: public education. While discussing the need for more providers, staff and clinics, patients described a substantial amount of confusion surrounding addiction and the pathway to recovery. Another patient in Missoula stated:

And I had heard about these methadone clinics and Suboxone programs and stuff, but the closest one that I knew about was Missoula and I lived in Saint Ignatius, which it's about an hour drive. And the other thing, from what I had heard, was you had to go in every day. [...] And so, I think that there should be more clinics, at least another one up North because I know that there's a lot of other people up there who struggle with addiction, and they might be in the same shoes that I was in and may be more apt to do something about it, if there were treatment options that were closer, that were just more realistic (Missoula patient).

This patient summarized the experiences of many patients across the state: they would have sought treatment earlier in their addiction if clinics were more accessible and public knowledge about the treatment process were more ubiquitous. For this patient, treatment was inconvenient and presented emotional, financial and time barriers that prevented his access.

Another patient described the lack of available spots in treatment programs and the preferential treatment people with open court cases receive. She sought treatment several times, was denied, and gained admission only once she had an active CPS case. She described her frustration with gaining access:

'Oh, well, you don't have any court cases. We don't have room.' You know? There was always an issue of why there wasn't room for me. I mean, I got on so many waiting lists, and this was back in November of 2017, and I have not got one phone call yet, and my name's probably on 20,30 waiting lists (Hamilton patient).

Besides highlighting the lack of available spots and difficulty gaining access to treatment, her comment reflects the need for a more active public knowledge campaign: she was confused and did not know whom to call for help or what type of help she needed. 
The lack of local public knowledge about addiction and treatment also leads to the public's perception and stigmatization of addiction. Many patients described the misperceptions and negative attitudes toward addiction, treatment, recovery and Suboxone. One patient in Hamilton stated: "The success rate of Suboxone. I would change how people view it, that they understand it better, and what it could do for someone who is addicted to opioids. They just don't know enough about it. If people [knew] what it did for addicts, it would be more widely accepted." Stigma is covered more thoroughly in the Stigma Report, but it is important to mention that patients express concern about the negative perception of medications used to assist in the recovery process and the stigma surrounding addiction.

\section{Co-occurring disorders}

Staff described several chronic behavioral health conditions as particularly challenging to address while treating patients for addiction. As the Missoula medical director stated:

You know, the ones that probably struggle the most are the ones with personality disorders. I'm thinking like borderline and things like that nature. It's very hard to work with them because it's always an up and down, on a dayto-day basis. One minute, they like you, the next minute, they hate you, depending on the time of day. And so, it's really difficult (Missoula medical director).

A Bullhook staff member relayed:

We do have that small percentage that are either like really still struggling, but it's not just the addiction piece. It's really complicated by severe mental health disorders or personality disorders, that kind of thing. They're struggling. Then there's a handful, and I think you will probably find this in any program, where they just were using Suboxone, misusing Suboxone, and they came. They weren't willing to see an LAC. They weren't willing to go inpatient, and so we had to discharge them from care (Bullhook RN).

A Helena BH director described:

I think sometimes, some of the really hard clients to work with are those ones that have co-occurring serious, disabling mental illness in addition to their substance use disorders, where there's other medication being prescribed in addition to Suboxone, and sometimes that's really hard for members of our behavioral health team to support at times. But I feel like those are also hurdles we're overcoming (Helena $\mathrm{BH}$ director).

Patients suffering from severe mental illnesses, polysubstance use (methamphetamines), and other behavioral health disorders face additional hurdles when trying to recover from opioid addiction. These conditions were noted as reasons for patients' lack of success with their recovery process or discharge from the program. Many of these disorders inhibit honest dialog, which is detrimental to a treatment model built on trust.

\section{Patient longevity}

The length of patients' time in the program affected their ability to earn staff trust. Providers described their frustration when they encourage patients to engage with behavioral health services to address co-occurring conditions but experience resistance from the patients.

There's a couple different kinds of MAT patients. There's one that has been in there a long time and they just ... they're so easy, they do great. And then you have the patients that have been in and out of opioid use disorder. Okay, so 50\% I would say are for honest and they're willing and they're not deceptive. And then you have some that are deceptive, unfortunately, and that does make life 
really tough. And it's so frustrating when they're deceptive because we make it ... so we try to create an environment that they don't need to behave that way. When they do, it's so frustrating (Butte NP).

Staff described patients who repeatedly dropped out of and reentered the program as problematic: they lack trust in treatment staff, and their deception sparked distrust from staff. Other staff commented on the need to engage and introduce new patients to the program, stabilize their medications and build relationships that facilitate their recovery.

Personalizing a program for participants promotes retention while a one-size-fits-all approach to treatment may lead to dropout. One member of the Bullhook care team noted:

\begin{abstract}
Because we've had quite a few patients who have been on it for quite some time now. They started with us right after we began and are still here. We wanted to figure out how to make it continue to work. I think it was basically, what had happened was Katie had had a couple of patients who belonged to Dr. A for primary care, and they're like some of our original patients so they were stable. So there was talk of we could just move them upstairs to medical instead of being in behavioral health. So then they were like, well, if Dr. A got her waiver then she could just keep her patients and then they're not seeing two providers again (Bullhook care team member).
\end{abstract}

The care team in Bullhook transitioned some of their stable patients to their primary care provider for addiction treatment to eliminate duplicate appointments, in an effort to make treatment more efficient for stable patients. The program builds trust among patients by preparing them for the potential internalized stigma they may perceive when switching providers. Further, they communicate the reality that no one is perfect, and relapsing does not suggest some moral failing. Care members treat patients with respect, building trust and enabling retention. The staff at the MAT programs we interviewed described adjusting and seeking new ways to relate to patients to bolster retention and reentry.

The pattern of personalization, personalized medication management, and personalized behavioral health management remained consistent across MAT sites, as this Kalispell provider noted:

I have a couple of people that I've had for almost a decade and that had an alcohol use disorder. So starting them on medication, has been sober, is functioning well, but is still remaining on medication to do so. Is resistance to engaging in any kind of formative treatment and at this point in time, if you've got 10 years of sobriety or stable on a medication, if you don't want to go see an LAC and are maintaining your sobriety, I'm not going to push the issue. Because I'd rather they remain engaged and, on their medication, and doing well (Kalispell waivered provider).

Staff noted that their approach centered on harm reduction, and if that meant omitting behavioral health or medication services within the program, they were willing to adapt to what fit each individual patient's path to recovery. Medication is an effective method to combat withdrawal symptoms, but this medication must be administered with the input of patients and a personalized approach to care, to ensure that patients fully engage with the program. Several staff reported having colleagues who disapprove of this approach, as they do not subscribe to the harm reduction model of care.

\title{
Administrative barriers
}

Staff also described several administrative barriers that staff and patients must contend with: 
But I'm trying to think. We're doing a lot better at actually having structured MAT meetings, so like talking about people that might be really struggling with relapse, and that's a team-based meeting. So that was kind of lacking, I would say, in the last year, but we've definitely tried to get back on track with that. We've had a couple of our first scheduled MAT meetings, and those have gone far better than they had in the past. So I would say that. And there's just really, like ... Me and the clinic manager have been having some ongoing conversations about just really making sure that our MAT participants aren't treated any differently than any client that gets services here at Helena Indian Alliance. So in terms of like, them being able to have say about when their own appointments are scheduled, or that ... just that there's continuity of care, and that they're not treated any differently than any person that's just here for a blood draw, you know what I mean? (Helena BH director).

Staff noted that being transparent and relaying information about MAT patients ensures that they receive the same quality care that any other patient would receive. Staff also described trying to achieve this continuity of care when patients become wards of outside agencies, such as the criminal justice system. One nurse stated:

There was a couple that where they ended up back in jail going through withdrawal and then just never returned calls back. We got a letter from one gentleman saying, "I'm here. Can you come and help?" And we couldn't. Then when he did get out, I kept trying to call and lost contact with him. I've heard from a couple people who had been on Suboxone previously and when back on, that Suboxone was the worst withdrawal they'd ever been through. I don't know if that maybe played a part in that particular gentleman not returning cause he didn't ever want to be in that position again (Butte RN).

This quote highlights the importance of integrating care with outside agencies-jails in this case-to continue treatment, manage withdrawals, and mitigate the risk that patients experience severe withdrawal from Suboxone cessation.

\section{Continuing Program Activities or Core Elements of the Original Intervention}

An evidence-based MAT care model can be structured in a range of ways; a recent Office of Assistant Secretary of Planning and Evaluation (2017) review identifies seven different staffing and delivery models that demonstrated effectiveness in clinical studies. Across SOR sites, there has been a consolidation of model types, with most sites using a nurse-care coordinator in conjunction with waivered medical providers and behavioral health staff, often in the form of LACs. This section of the report presents the broadly defined core components of the treatment model: staffing, waivered provider capacity, support staff capacity, peer support specialists, team-based care, prescription medication, psychosocial services, and recovery services.

\section{Staffing}

Having a stable, cohesive staff benefits patients and the morale and productivity of the team. One Butte RN stated: "We do really good about processing with each other and that helps a lot. Yeah. Yeah. This is the most supportive team I've ever been with." Having a management team that takes their staff's professional well-being into consideration enables MAT staff to provide better care while also preventing burnout. For instance, a Hardin executive stated: "I think even folks who have missionary zeal when it comes to this work, do face the risk of burnout if they have these unrealistic expectations of what their role is, and what they can do." 
Burnout can lead to staff turnover, which may result in a decrease in care as new staff are recruited, hired, and trained. The Polson program manager stated:
Whenever there are staffing changes, then there's big hang-ups of waiting on, depending on the type of provider, credentialing perhaps. So that they are fully credentialed and can bill. And then that puts delays in care. And then too, just people getting a feel for each other and how the program works, and then different skill levels and competency of different areas. I think anytime there's a turnover in staff, that sets you back some steps, of having to redevelop and reanalyze who are the best players for different aspects of the jobs (Polson program manager).

Retaining a well-qualified and capable staff enables MAT teams to offer consistent care. This participant also mentioned that getting to know each staff member and how they work takes time that would otherwise be dedicated to patients. When staff members know one another, they can anticipate when their teammate needs a break. This Butte RN reflected: "Yes. And that we do support each other that well. And we read each other really well too. I mean, I didn't have to say anything after interacting with a difficult patient. Lisa said, 'You're going to go take a few minutes for yourself.' And that was wonderful." Maintaining continuity in staffing enables staff to look out for one another's best interest, which may in turn be in a patient's best interest.

\section{Waivered provider capacity}

Staff reported that some of their peers in their clinics hesitated to seek approval for the Drug Addiction Treatment Act (DATA 2000) waiver which enables providers to prescribe medication for opioid use disorders. Once clinics had established a precedent for this treatment, many described efforts to expand their capacity within their clinics. A Bullhook staff member said:

Well, she's one of them that just got her waiver and so we're really excited. [...] And both Katie and I increased our waiver number to one hundred so that we can each have a hundred patients. [...] As we've changed or as we got more clients, myself and the PA [physician's assistant] I work with have gotten our waivers with the plan that we would transition our stable patients to primary care more (Bullhook BH manager).

Increasing the number of waivered providers within a clinic enables BH staff to focus on the newest, most unstable clients. As a Bullhook team member mentioned:
That was our goal to be increasing availability at this time. That's why we had two more providers waivered. They were going to take most of the patients we have on the program now, are very stable, and allow for us to start taking more unstable patients (Bullhook PA).

Programs hope to increase their patient capacity by recruiting providers from within their organization. This Butte executive mentioned: "As an organization though, we have tried to ask every medical provider who works [with us] to become waivered. But I would say for the most part, we're almost at 100\% of our staff waivered." To achieve this, Butte has normalized having all their medical providers receive a waiver. By expanding internally in this way, programs hope to reduce some of the recruitment challenges facing sites seeking external support.

Some programs have reached the maximum number of waivered clinicians and must expand their capacity outside their organizations. The Polson program manager stated that the program seeks to expand capacity by "reaching out to the schools to do nursing continuing education credits. So, we're hoping to reach out to the schools and offer teaching education 
credits and then the nursing credits." As sites expand the capacity of their waivered providers, they will need to ensure capacity of other roles as well. The Missoula medical director explained:

I would imagine there will be a point in time where Deb's going to start getting overwhelmed, where there's too many clients on the plate, and so I'm not really sure how many clients each nurse care coordinator can reach, but I've kind of put a number in my head of once we get up to about 100 clients on our roster, we should really look at it. I'm thinking 100 is about 25 a week, that's, to do this well, that's at least evaluating six patients on a daily basis [inaudible 00:06:44] (Missoula medical director).

\title{
Support staff capacity
}

As waivered providers and the patient population increase, other staff roles may become overwhelmed.

Most participants identified a staff member that served as their team's most valuable staff member: a liaison between the staff and patients. In Butte, the staff identified this person as the MAT RN:

\begin{abstract}
We were able to secure other grants [...] and with those grants we were able to hire a MAT nurse. That's Chris, and that's really been a tremendous part of the program. Just because programs do try to operate without a MAT nurse where they just treat the patient as any old patient. [...] There's just a lot of hands-on need. So the previous grants allowed us to hire the MAT RN, which like I said, was just huge to the success of the program (Butte prescriber).
\end{abstract}

As Butte staff members described, the MAT RN provides several program elements: care management, scheduling, and oversight services that keep patients motivated and engaged and help staff stay prepared for their jobs. In other locations it is other staff members who fulfill the most valuable staff role that the MAT RN accomplishes in Butte. In Hardin, staff stated that the behavioral health care manager, like the RN in Butte, acts as a care manager, a behavioral health care manager, and a clinical provider to offer personalized care to patients. Staff in both Butte and Hardin stated that having staff that can adapt to the most pressing role benefits other staff and patients.

Elsewhere, recruiting the proper support staff proves challenging. The Blackfeet manager stated that recruiting care coordinators, LACs, and peer support specialists was "really slow with the Blackfeet tribe because nobody was applying." Slow recruitment and turnover of certain staff members, such as the MAT RN or the behavioral health care manager, would affect the program's ability to provide treatment for patients.

One Western Montana Mental Health Center (WMMHC) participant described:

If there was a need for an additional prescriber, an APRN at that site, who would take on the bulk of the IMAT, the Suboxone and the different things, prescribing work with that team more exclusively. And those, we were getting applications rolling in for that position as well as the coordinator position. And then we sort of had to shut things down (WMMHC BH service director).

Staff shortages and heavy caseloads present challenges for the current staff. The hiring freeze further exacerbated the staff's ability to fill open positions and complete their work.

The quality of communication and collaboration among staff members also affects the care clinics can offer. For instance, a Blackfeet care manager stated: "I guess change the way we work as a team. I feel like there's a real breakdown in communication, and it's on a personnel level. We have to communicate as professionals and be respectful to one another." In this 
instance, a miscommunication led to a patient being transferred to another program without the care manager's knowledge, which reduced her preparedness for when the other program called for information.

\section{Peer support specialists}

Although not all SOR sites use peer support, within those that do, peer support specialists play an important role. Those sites subscribe to one of two models: internal peer support specialists and external peer support specialists. Polson, Missoula, Helena, and Blackfeet follow the most common model-internal peer support specialists who are available to patients at all hours-which was documented extensively in the STR report. In light of the complications and challenges surrounding the peer support specialist role, several sites use external peer support specialists. The Butte MAT RN contracts with peer support specialists from outside the organization: "We use SMART's peer supports because we haven't been doing this long enough, but I'd like to see that-somebody really involved with that." Because the Southwest Montana Community Health Center is a newer program, staff opted to contract with outside peer supporters because they believed their SOR grant money was better spent on peer support specialists affiliated with an existing program who could handle their current enrollment, but there are plans to initiate this service within the clinic.

Other sites, such as Big Horn, prioritize professional roles over peer supporters owing to a lack of access to eligible candidates and a preference for staff with professional training and degrees in behavioral healthcare. For instance, a Big Horn manager stated: "But if you have to pick a peer support versus someone who is a professional pursuing that degree but has some of those components, I think that there's both ways to look at it. And actually, care manager/ LACs seem to be the strongest in that peer support role." Big Horn does use an external peer support liaison, funded by a community-based grant, who refers patients to the program. It should be stated that staff in Hardin and the Big Horn Valley Health Center are not entirely opposed to the idea of peer support. They value that role but are skeptical of the financial value an internal SOR-funded peer supporter provides based on the current training time, certification, and billing structure for that role. By contracting those services to outside agencies or to a community-funded position, they save time and money, enabling them to focus on the professional roles they view as more cost-effective and valuable for patient recovery while also making peer support available to patients who express interest in this program component.

\section{Team-based care}

Patients and providers benefit from the team-based care offered at SOR MAT sites and the relationships they form with staff. The value of relationships with staff extends to the context of care, especially with stable, well-integrated teams. Many sites report little staff turnover. A team is mutually reinforcing, providing the patients with a group of individuals to whom they can be accountable and from whom they receive encouragement and engagement.

\footnotetext{
But I really feel like that our clients on the MAT program truly get that teambased care, and they truly get that whole-person treatment. So from the counseling aspect to the peer support aspect to the medication aspect to the physical health aspect, I really feel like we do a really good job of just looking at every aspect of a person's life and trying to really help them reach long-term recovery. So I think the biggest benefit of the program is just that. I think it gives the person the highest chance of long-term success and long-term remission. I think that's the coolest part about it (Helena BH manager).
} 
Well, obviously the medication itself, and I think that Caitlyn was super, super effective. I didn't feel like our next provider was as on top of things and effective, and I feel like Dr. $M$ is like super effective too. I think when they have someone like Dr. M who really reinforces the global picture like I do when I admit them and try to follow them. As far as what program are you participating in, what's going on at home, blah, blah, blah, you're looking at the whole picture. I think that's one of the most beneficial things, is that it's a complete picture. It's completely integrated. We want to know how, not just how your medication is working, and how effective is that, but what as a whole is going well in your life. So I think that's a big, big, huge piece, is that focus being there (Missoula coordinator).

Staff describe that building trust enhances their rapport with patients and emerges as the most important component of care. Trust informs the ways in which patients receive dosage recommendations, experience the care team, and engage with the organizational setting of the MAT programs. Site staff report that they use this trust to encourage engagement with broader healthcare, both behavioral health and physical health, an encouragement that ripples throughout families of those who are receiving care.

Patients were positive about the treatment provided at all of the SOR MAT clinics throughout Montana. Participants spoke positively about the care, staff, and treatment modalities offered. When asked "What should the clinic never stop doing?" one Bullhook patient stated:

Oh, well I like how friendly they are. And the way that they listen to me [.. .] I don't know, I kind of look forward to going in there, talking to her. I like the way that she checks up on me, I guess. She asks questions about, that other doctors don't really ask, more personal questions like ... "Okay, so you said earlier you like fishing." She doesn't know anything about fishing, but yet she'll try to kind of connect with you on that level because that's where she can connect with you. She'll ask questions about... when you go in there it's not just straight to the business straight to the point. Well it is, but at the same time she makes you feel comfortable while you're in there (Bullhook patient).

Patients described a comfortable environment in which they received personal care and attention. Staff were professional and made efforts to make personal connections with patients, and patients in turn felt staff respected their time and life experience. Another Bullhook patient stated: "I like how they work with you around your schedule." This patient believed that respect for one's schedule conveyed a deeper level of respect for individuals. Another patient in Polson agreed that the staff at the MAT clinic respect her time and make it easy to schedule appointments. She stated: "[Nurse] comes down [to Ronan] once a week on Fridays. So, then the people who live in Ronan, they can see her in here." Staff have made treatment more accessible for patients living farther from the clinic.

Participants described the positive attitudes among staff as a bright spot in their daily lives. One patient from Butte reported:

They should just never stop being as supportive as they are. I have never, even during a hard day when I was super stressed and freaking out, all they did was be positive and uplifting. I've never heard anything negative out of their mouth, not one time. I've never heard anything but positive, uplifting. They're kind of like a pep team. [...] They should never quit being like that because that's what somebody needs when they're on the verge of so much change in their life. It's scary. Even if it's good change, it's still scary (Butte patient).

This patient appreciated the staff's positivity and general demeanor toward patients in recovery. The attitudes among staff served to destigmatize patients' addiction and make them feel accepted. This patient also told a long story about the dependability of staff. She 
elaborated on a time she called the local crisis line to report her friend being left for dead by his "friends" after he overdosed. The crisis line never called her back, but the nurse at the MAT program did, and that compassion and dependability meant a lot to her.

Another Butte patient appreciated the harm reduction model and staff's lack of judgment. He stated:

They've been really great. I told them I didn't want to quit meth. They were like, "Okay," but they still worked with me, talked about it with me, and they still pressured me, and I liked that. I liked the fact, like the pot, no one's going to stop me on that. Don't even waste your time. If you don't think it does stuff good medically, well, that's your opinion. I really do think it does (Butte patient).

This patient uses several substances in addition to opioids but is most concerned about his opioid addiction. He believes his recovery from opioid addiction depends upon Suboxone and resuming use of other substances, such as methamphetamine and marijuana.

\section{Prescription medications for treating OUD}

Suboxone is the most prescribed medication at SOR clinics. When providers deem that patients are susceptible to relapse or may divert their medication, or when patients are unwilling or unable to reliably self-administer their Suboxone strips, providers seek to administer alternative medications, such as Sublocade. This Butte executive decided to prescribe a Sublocade injection for a patient who had "a lot of resistance [...] But it's like some people, when they're a little iffy on the program, they want the ability to not take their Suboxone. And also that choice to not take it so that I can use opioids this weekend." The Butte executive described Sublocade as the preferable medication for patients who show instability after induction-because of either relapse or missing dosages. Because providers inject Sublocade about once a month it can be difficult to monitor a patient's progress with the medication and any reactions they may have if they continue to use methamphetamine or other substances. Sublocade is also the preferred medication for patients with extenuating social circumstances, such as transportation, scheduling, and administering barriers that preclude them from regular appointments.

Sublocade does pose some concerns. For one thing, it is painful when administered. A Butte NP stated: "They quit showing up. So I think the problem with Sublocade is that we inject it, and then they don't want to come back for that next one." For many patients, the pain of getting Sublocade outweighs the potential benefits. In addition, not being able to have Sublocade on site presents a challenge to providers and patients. Sublocade requires a pre-planning process that may prevent its use among patients who would benefit from it more than from other medications. However, as previous participants note, Sublocade is much less likely to be diverted owing to how providers administer the medication. Thus, providers interviewed for this evaluation viewed Sulocade as the best option for patients who struggle with medication dosing adherence or pose a high diversion risk.

The stabilizing effects of medication were identified as the most common essential component of the MAT program, as articulated by this care coordinator:

He can't work and struggling every day, trying to raise a child, and living in that shame almost. And he said that he felt the best that he had felt in 12 years, and I just can't even imagine. I think it changes it from using a drug to taking medicine (Bullhook care coordinator).

Many patients view being on any form of medication as switching one drug for another. Some patients see using any drug as a problem and prefer the abstinence model. Personalizing medications can thus mean managing patients' willingness to take their 
medications. One Blackfeet LAC stated: "And a lot of them talk to me about that. They're like, I want to get off Suboxone. That's why I come here. I don't want to be on it." The pressure patients face to reduce or cease using medications may affect their willingness to readily take Suboxone.

Staff are well versed in Naloxone, as the Blackfeet care manager noted: "We did the Naloxone training. So we're all master trainers; if a client does come into our facility that has overdosed or is inert, we can assist them until medical help comes." Thus, participants were trained and ready to use Naloxone in case of emergency, but its use throughout the community was unknown. A Bullhook CEO reflected: "Yes. Everyone gets that. [. . .] I think I've heard of one story of it being used, but I don't know of any more." Another participant described the process of educating patients about Naloxone:

When I educate them about the Narcan and say, "Hey, this is what this is for, use it on someone that you find down or you have it with yourself and let people know that you're in treatment for this." And so if they do find you down, they know where this is and how to use it. And they haven't ever recalled some anecdotal like, "Oh yeah, so and so used that." I don't get a bunch of feedback on whether or not that's been helpful. But I'm sure they've been using it (Butte NP).

Participants describe teaching patients how and when to use Naloxone and how to tell acquaintances that they have this medication in case of an emergency. The overall low level of awareness of Naloxone among community members, as noted by providers, continues to be an important issue to remedy.

\section{Perceptions of medication by patients}

Patients enrolled in Montana's MAT programs generally supported taking medication to reduce withdrawals from and relapses with illicit drugs. All patients expressed gratitude for the programs and wanted to ensure that they continued. One patient from Big Horn stated:

Keep this program going. Honestly it should. It should be there $100 \%$ times 10 for the people like me, for my friends. I told all my friends, be on this program.; Honestly, you'll be so blessed. I said, "I want to live a long life. I'm sure you do." And I have a couple people that are cancer patients that are on opiates, and one of them, she actually beat her cancer. She's cancer-free, but she's still taking opiates. And I'm like, "Gosh." I'm trying to fight her through with this (Big Horn patient).

This patient credited her successful recovery to the MAT program and Suboxone. She also described additional demand within the community and reported that the MAT program is valuable to others who have yet to enroll. Other patients discussed the value of their program. A patient from Butte stated: "The biggest thing for me was this is the first and longest time that I've been able to stay sober in my entire life-one year doesn't seem like a lot, but to me it's huge."

Patients express support for the MAT strategy and credit it for their sobriety. Other patients see similarities between Suboxone and other medications they take. This patient in Hamilton stated: "I kind of look at Suboxone as the same way as I look at my antidepressant. It's just something I need in a balance." Another patient in Bullhook described it similarly: "Diabetics have medication so that they're better. They have to use their medication. That's how I feel like this is: we have medication for a different disease and we have to use it in order to get better." Some patients described in more detail their perspective on Suboxone and what it has done for them. One patient in Butte explained:

Okay. I would say it's not a drug. It's more like a stepping stool, like a crutch, that you can use, so that you can go to work and do stuff at first. You can get 
away from all kinds of people, so you can get out of that scene because you already have that part that makes your brain and body okay. You don't have to go and look for that, you already have it. So you can spend your time, instead of looking for drugs and spending all your money on drugs, you can go out to eat and do normal things. You're not high, so it doesn't seem unreachable or you're so high you're uncomfortable. It's just a maintenance where it's already there, you don't have to continually think about using drugs and getting drugs every day (Butte patient).

The MAT program provides patients with an opportunity for recovery and a new handle on their lives. Rather than living for the chase and associating with people who keep them in a cycle of addiction, the program enables people to escape.

\section{Diversion}

Diversion of medication leads to a negative perception of MAT programs and impedes providers' overall intended work. Internal program protocols that focus on building trust, supporting open communication, and encouraging patients to be honest about their medications promote a culture of trust between patients and staff. Despite this level of trust, participants report that their patients divert medication. One Butte participant commented:

[Strips] go for decent money. But it can be frustrating knowing that if [they're] selling half their dose that they are paying their rent, or your mortgage, and it can be very frustrating, and I think that's probably our biggest frustration when we're concerned that people may not be taking their dose entirely. [. . . I keep telling myself it's for the greater good. You've got to keep telling yourself that (Butte NP).

This participant describes the internal battle many patients face when weighing the advantages and disadvantages of diverting their medication while trying to abstain from illicit drug use. From a staff perspective, it is difficult to monitor every patient's medications from afar, and attempting to do so might even negatively affect their relationship with patients during the trust-building process. To cope with the responsibility of providing diverted medications, staff coach themselves to look at benefits of diverted medication rather than its negatives. However, staff expressed several concerns about diversion, as expressed by this Blackfeet manager: "Probably meth. [...] So what they're doing [...] is they're selling their medication, the Suboxone, and getting meth or whatever else or using with the medication they sell."

\section{Patients' perspectives on diversion}

Patients report that SOR clinics are sources for some diversion. Patients speak about diversion in two ways: (1) for illicit use, and (2) for self-medication. Some patients describe selling medication diverted from SOR clinics for illicit use to make money and to get high. One patient in Butte discussed the financial incentive to sell extra Suboxone strips:

When I was on Suboxone, they gave me two, eight-milligrams strips a day. I only needed one. That was coming off of two grams of heroin a day. I only needed one of those strips.

[Interviewer] So what did you do with the other one?

I sold it. That's another thing. Suboxone . . . because people buy them. For 20 bucks a strip or 20 bucks a Subutex pill.

[Interviewer] So why do people buy them? 
Well, I know the strips people buy for when they're withdrawing off of heroin and they're not ready to quit using heroin, but you can get high off of Subutex. [...] If you shoot it, you can get super high off it. I used to purposely buy Subutex to get high off of it (Butte patient).

This patient described the extra money patients can make off the excess medication and the ability to get high off Subutex. Some patients are opportunistic and sell their extra medication, perpetuating addiction within their communities. The amount of Suboxone and illicit drugs in a community drives the market for diverted medication. Patients described knowing the current rate for Suboxone in town, as people would ask patients to sell them their medication.

Diversion presents patients with a tempting income opportunity, and if the diverted medication is used for self-medication, they may rationalize their decision as "helping" a friend through their withdrawals. This is the second way patients describe diversion: for self-medication. By diverting medications such as Suboxone, these patients increase the supply of Suboxone in the community that people may use to limit suffering from withdrawals. One pregnant patient in Hamilton discussed her dependence on diverted Suboxone to try to protect her unborn child and to avoid the judgment of healthcare staff:

See, when I went in my first doctor's appointment with my son I decided I was going to do everything the legal way and try to get on the Suboxone program. So when I went in and I talked to my OB at first I explained to her, "I am addicted to opiates and I don't want to use while I'm pregnant, and my other kids were taken," and whatever. So I confided in her that I've done Suboxone off the streets before. [...] So right off the bat she just looked at me different and just made the whole situation uncomfortable for me. So my second visit when I went back, I just told her, "I kicked the habit on my own," whatever, when really I just went and bought a bunch of Subutex off the street. And instead it was that stigma and the judgment and just made it all uncomfortable to where I didn't feel like it was a good idea to tell them. So I did Subutex three-quarters of my pregnancy actually. It was crazy because one pill would last me eight days to where I'd have to have 10 Hydros to last me a day. So it kind of made me feel better about myself that I wasn't trying to harm my baby. And it's like the person I was getting them through, she was prescribed them because she was pregnant. So I knew that it wasn't harmful, because obviously they're not going to prescribe somebody who is pregnant Suboxone, and it's better than doing a bunch of Hydros (Hamilton patient).

Patients describe a high level of difficulty gaining admission to MAT programs, and this factor, combined with the stigma associated with admitting to addiction, inhibited this patient's admission. The lack of access to treatment and stigma in the community can lead some patients, like this one, to regulate their own doses based on their withdrawals.

Another patient discussed the drug supply in Missoula and the need for addicts to selfmedicate to alleviate their withdrawal symptoms when drugs are scant.

So Missoula itself, I mean one week, everyone has shit here, and instead of \$30 a point, it's \$10 a point, and everyone's competing, and ... And then the next week, everyone's sick because no one has anything left, and literally no one can get it. And it can run like that for a week or two before more shit comes back into town. And I've seen people go there [MAT clinic], and say that they want help and they're ready to change... And then soon as there's shit in town, they're right out of it selling whatever they have left of their Suboxone that they got, or trading it for dope (Missoula patient). 
This participant described a low drug supply in town as the major catalyst for joining MAT programs and diverting medication. This patient also conveyed cynicism among a percentage of patients who drop out of treatment: they are there only to divert their medication and/or ease their withdrawal symptoms. Diverted medication can alleviate people's withdrawal symptoms, but paying for it poses a financial barrier. One Bullhook patient described the expense of diverted medication:

Yeah, it was a struggle... I live on a low income, so you know just the money situation itself and my husband and I both having to treat our withdrawals. We would be good one day because we'd make $\$ 20, \$ 30$ to be able to get a strip and then, two days later we'd already be in withdrawal because we're broke and can't ... You know, it wasn't a stable way of how we took it, it was a struggle. I was sick like every other day or every other weekend. It just depends on, like I said our money situation or... And so it was tough. [. . . L Like I said having to buy them on the street it was ... People were charging, \$40, \$50 a strip sometimes. And, I mean now, people can sell them for $\$ 20$ (Bullhook patient).

The Bullhook MAT program inadvertently altered the illicit Suboxone market in the greater Havre area. This patient described the difficulty she and her husband endured trying to buy diverted Suboxone before the Bullhook clinic opened. She ultimately joined the Bullhook program to maintain a stable condition and because it was so expensive to buy diverted Suboxone.

\title{
Psychosocial services
}

MAT patients do not always elect to use the behavioral and mental health resources available to them. Every program reported trying to engage patients in mental health services, and their efforts were often met with resistance. Creating groups for patients who take medication for an opioid use disorder may alleviate some of the stigma associated with MAT; however, requiring attendance might make recruiting potential participants more difficult. Welcoming people with co-occurring and polysubstance use disorders may help increase membership in groups as many patients struggle with more than one substance and restricting the group to opioid addiction limits participation. However, participants at many sites report a lack of interest in mental health services. A Butte RN commented:

\begin{abstract}
We're struggling with getting the patients to see how valuable behavioral health is. [.. . A lot of the patients that come in and they're usually somebody that's with probation and parole, they're required to attend either AA or NA meetings as part of their probation referral. But the biggest struggle, I feel like we're having is getting them to understand behavioral health would be a good key component of this to find out the root of the problem. There's a reason that we turned to substances, unless we get down to the root of it, that's just kind of this always underlying current. And we do have a few people who are active with behavioral health, but not as many as I think would be very helpful (Butte RN).
\end{abstract}

The Butte RN described a reluctance to engage with mental health services unless required by probation and parole. Turning Point was the only program to formally require patients to participate in mental health services. As this coordinator stated: "If they aren't doing any wraparound services, because they've refused, we will say, 'You know what? You have to do a minimum of therapy once a week." Most others that made it optional struggled to recruit patients (in the next section patients describe reasons for the low attendance at group therapy).

Helena initially struggled with its group therapy format before solidifying a working model. As the Helena peer support specialist stated: 
We have a MAT group here, so that's something that we've been doing since October of last year, and it was kind of a work in progress, and we had it down almost to a fine science by the time COVID came around and now offering that virtually. We just have smaller groups now. And honestly, it just worked so well, and our participants loved the cognitive-behavioral part of the program that they go at the same time, and our no-show rates have decreased because everyone knew there was a set time every week where they had to be there (Helena peer support specialist).

In Helena's case, adding staff, improving scheduling, allowing people with co-occurring disorders to participate, promoting the group as an option rather than a requirement, and offering a virtual option have strengthened its group therapy model.

Sites that care primarily for an American Indian population expressed interest in improving access to services tailored to their cultural context. A Blackfeet manager stated:

Maybe with this new SOR grant, we can get some people from the community who are spiritual leaders who can come in. I really see the cultural aspect helping people, a lot of people. Within our culture, that's a big part of our life. And I noticed a lot of my clients, when I do my assessment with them and prepare the care plan, I noticed a lot of them, a lot of their lifestyle I guess, is based on traditional ways, ceremonies. That's their way of healing is through their culture. So their care plan is based on getting into the clinic, getting medicated. Not all of them want medication. Some of them don't. So they'll work on getting their basic needs met. A lot of them are homeless. A lot of them want to do their reunification plan so they can reunite with their children and build their life back together. I guess that's about it. Oh, and then if they don't have a reunification plan, not all of them have an open case with CPS. Some of them just have an opioid use disorder, and they're wanting things offered in our program that will help them keep them busy (Blackfeet manager).

This manager highlighted her eagerness to personalize the program for patients. By seeking out ways to engage patients through their cultural and spiritual beliefs, get them housed, tailor their medications to their desired recovery plan, and aid their progress with CPS, MAT program staff seek to personalize the program to ensure patient retention and fulfillment of patients' goals.

\section{Patients' perspectives on group therapy}

Patients highlighted some shortcomings and areas for improvement of the group therapy programs. Some patients described that a program's inclusion policy may detract from their opportunities to benefit from group. One patient in Missoula captured this problematic dynamic:

Literally, there was another guy in there who, I don't know, me and him just seemed to be bullshitting a lot, and literally, before the end of it, he's like, "Oh hey, here's my number." Like, "Oh, by the way, I can get you whatever you need, aside from here, even though I'm trying not to use myself, but I still got the hookups." That's literally what it turned into. So it was like, I just found a new dealer. That's literally what happened, was I found a new dealer when I went to that group. And he was court ordered. [...] It's literally like a hub to meet a new dealer, in my opinion, because they're forced into going. It's not as strictly a voluntarily group (Missoula patient).

This patient described group therapy as a place to meet a new dealer. As the Butte RN described in the previous section, requiring patients to attend group may detract from its effectiveness and degrade the overall quality of interactions. Many patients attend group 
counseling to seek solace and support from others, but some patients use group to encourage patients to relapse.

Patients also discussed the meeting times for group therapy as a consistent problem. A patient at Bullhook shared:

The only one thing I could think is maybe offering a group counseling for a group of people that was maybe at a later time in the day where everybody... Because a lot of people are working at 9:00 a.m. on Tuesdays. Maybe if we had like an evening one or a late afternoon meeting that maybe more people would be able to participate in... Yeah. It's really not designed for people who work: group counseling. As far as the appointments and stuff, they're really good about getting you in after your work time and all of that. They really work with you because I work for the schools, so I get off about 3:00 every day, and they're really good at making after 3:00 appointments for me. It's just that one group counseling that they only have at 9:00 a.m. (Bullhook patient).

Another patient in Missoula discussed the inconvenience of group therapy:

And groups always run at really bad times. I've always been a worker. I've never had periods of time that I didn't have one job at least, if not two. So when I have a Monday through Friday 8:00 to 5:00, and group is only 1:00 to 3:00 or whatever, it starts at 4:00, 4:00 to 6:00, it makes it almost impossible for anyone that's trying to have a professional life, a professional work life, to get any help (Missoula patient).

This patient would like to participate in group therapy but because of the available meeting times, she is unable to do so. She described how staff accommodate her work schedule for her personal appointments but scheduling for group therapy does not account for people's work schedule.

From Bullhook to Missoula, patients were interested in attending group therapy but unable to do so because of the timing of meetings. One Missoula patient expressed his frustration:

So even if they had a seven o'clock group, it's not like I'd be able to go. And then weekends. You can't find a professional in this field to do a group on a weekend. It's unheard of. And I have weekends off, so if I did have to attend a group and there was one held Saturday at noon or 2:00 or 3:00, you know what I mean? It'd be 100 times easier to be in compliance with the requirements of the program that you're trying to run, and still be able to receive the help I need aside from that (Missoula patient).

Patients who worked during weekdays expressed the most frustration with the meeting times for group counseling. They requested counseling sessions that fit their busy schedules, either after work or on the weekends. They perceived that the program was designed for people who did not work and could attend in the afternoon on weekdays.

\section{Recovery supports}

The lack of local resources to support recovery hampers patients' potential success. A Bullhook care team member stated: "If I had a magic wand it would be to have more support services for these people. Such as transportation so they can get to their appointments in a timely manner." A Big Horn MAT nurse suggested that resources could be better used to educate the public about how to recognize addiction: "Definitely a resource maybe for some education, community outreach, different things to show people this is what [addiction] looks like. This is what you need to watch for. These are the things you do." This nurse described the need for additional social resources, such as education, training, and community outreach, 
to help community members recognize the signs of opioid use disorder and not conflate it with use of alcohol or other substances.

\title{
Maintaining Organizational Practices, Procedures, and Policies
}

Care is delivered within specific organizations that have specific practices, procedures, and policies that may support or hinder delivery of effective MOUD care. This section presents specific practices, procedures, and policies that shifted or were maintained during SOR, including staff training, processes for client enrollment, tracking of program activities, program sustainability, outreach, and the functioning of the hub-and-spoke model of care.

\section{Staff training}

Participants in this report credit their training for the effectiveness of their programs. Trainings that addressed the integrated care model were particularly helpful. This Hardin participant reported that their work with the AIM Center at the University of Washington in Seattle enabled them to provide more effective integrated behavioral healthcare:

\begin{abstract}
We sort of thought that we understood how to do integrated care really well and learned that we really didn't, and their team of coaches and trainers helped us really hit the reset button. We began sort of doing things well, and they really helped us figure out how to make that integrated model work. And it really comes down to mechanics of certain key people. We wound up with the title, behavioral health care manager. I think they started, but essentially, it's a person who is the primary intermediary working with patients directly, facilitating their ongoing relationship between these intermittent face-to-face encounters in the clinic (Hardin executive).
\end{abstract}

The Hardin executive reported that access to trainings outside the state of Montana benefit their staff and promote the services they offer. Participation in these training courses better prepares Hardin staff to tackle integrated care by helping them create positions responsible for integrated health. Having staff whose role is to communicate with primary care and behavioral health providers ensures that patients receive wraparound care from wellinformed caregivers. Big Horn Valley Health Center (BVHC) staff in Ashland commented on the quality and need for more trainings: "So what I would love to see is an increase in MPCA [Montana Primary Care Association] offering those MAT trainings again, or all of their trainings. They fill up so quickly for the few that they offer. [...] I would really prefer to see they were doing almost monthly." This Ashland provider described a need for increasing the frequency and accessibility of trainings to provide new, less experienced clinicians with opportunities to learn.

Additional learning opportunities would also benefit those clinicians charged with treating patients with stimulant use disorders. The Helena behavioral healthcare director stated: "In terms of people who come into our clinic, who their primary drug of choice is stimulants or methamphetamines, that's kind of a target area we all are looking to get more training in." A few clinicians stated that until they received training on opioids or stimulants, they were uninformed about addiction and the drugs covered in the training. A Butte MAT prescriber described this education process:

Before that training, I really didn't have a great idea of opioid addiction, and I think I was pretty biased in my thinking. The training really helped me to see addiction as a chronic medical condition and to see the tremendous benefits of Suboxone in that patient. I think after going to that program and knowing that while I don't necessarily think opioids are Butte's primary problem. But there's absolutely an issue with it (Butte prescriber). 
The Butte prescriber explained that the training she received helped mitigate the stigma she ascribed to addiction. The program also aided the participant's perspective on what substances pose the most risk for her community. However, recruiting staff members who already possess this competency can prove challenging:

I think with any job, it's challenging to get the right individuals in the clinic setting, especially in our population. There's so much stigma attached to our clientele, so much misinformation, poor education, and even on a professional basis. And even when we hired the new nurses coming, and then I help with the interview process and you can have a great resume, lots of experience. But it's being able to have cultural competence and setting your biases and your opinions aside, and truly helping people who really need it (Blackfeet RN).

Some areas in Montana benefit from a diverse staff knowledgeable about their patient population, but recruiting and retaining a competent staff can prove challenging. In addition to understanding addiction, some staff are well versed in the cultural norms of the relevant populations, while those from outside the community might benefit from cultural training.

Participants also suggested educational, training, and networking opportunities that would empower them to improve their programs. Some suggested Montana should offer more opportunities within the state, while other staff suggested that programs could learn from other states. One Butte Executive recalled: "I think maybe we talked about a collaborative approach that we could learn from other states, and they could learn from us." Engaging with other states and learning from clinical peers may provide SOR MAT program staff with valuable professional contacts that could improve the care they provide. Other participants, such as this Big Horn program manager, discussed opportunities to improve Montana trainings: "I don't often hear about MPCA ones. So I think catering to a MAT group and being able to send that out and say 'This is local to Montana.' Not just a national webinar-FYI, your state peers are going to be on this call listening to this expert." This participant valued the opportunity to learn from experts about how their information pertained to Montana and MAT treatment throughout the state.

The Big Horn participant described trusting the information provided by the MPCA but would like to see more deliberate engagement with providers. Other participants offered more ambitious networking opportunities, such as this Ashland provider: "I would love to see an opioid summit . . by county or region, the people that you're able to meet, the community networking you're able to establish, I mean, so many of these programs are built around what is your community coalition or what is your community partnership." Echoing the Big Horn program manager above, the Ashland provider values the opportunity to learn about MAT in Montana from her peers. The Ashland provider also suggested expanding professional networking opportunities beyond the state and proposed an opioid summit as a means to disburse information. Other staff, like the Bullhook LAC, described the coordinator opioid group monthly calls facilitated by AMDD as helpful.

Overall, staff agreed with the Bullhook care team member that "more training from experts would also be very helpful." The community reinforcement and Matrix models were viewed as expendable. Staff also suggested, however, expanded training on medications. A Bullhook LAC noted: "It would be nice to have more information on how the Naltrexone and Vivitrol really work with the alcohol [. . .] because it's so much different than the opiates." Expanding medication training would better prepare staff to understand the effects patients are experiencing and educate them on potential side effects. Having a better understanding of special topics and populations such as pregnant patients and people suffering with chronic pain would enable staff to more accurately report outcomes to the state. 


\section{Processes for MAT programs}

Many participants noted that success is time sensitive; this Kalispell care coordinator stated, "You know, they can't wait three months for something like that [induction]. It's a pretty urgent thing. [...] If you can't get them in within a week, most of them are probably going to use again."

Many of the participants discussed changes that their programs had made to improve services. Team coordination emerged as the predominant theme; some programs made significant strides to reinforce coordination among staff, while others described needing to improve in this area. One Helena $\mathrm{BH}$ director described the following changes to strengthen team coordination:

But I'm trying to think. We're doing a lot better at actually having structured MAT meetings, so like talking about people that might be really struggling with relapse, and that's a team-based meeting. So that was kind of lacking, I would say, in the last year, but we've definitely tried to get back on track with that. [. ..] We've had a couple of our first scheduled MAT meetings, and those have gone far better than they had in the past. So I would say that. And there's just really, like... Me and the clinic manager have been having some ongoing conversations about just really making sure that our MAT participants aren't treated any differently than any client that gets services here at Helena Indian Alliance (Helena BH director).

An executive in Missoula relayed:

And so, I think, probably the biggest thing we've implemented is, since I've been coming out, is at least once a week we're meeting and doing staffing once a week with my nurse coordinator, myself, and the counselors so we can best discuss those cases individually to make sure we're on track and they're staying on top of it. I would say that's probably been the biggest thing that we've actually got going, better collaboration between the three houses, medical, nursing, and counseling (Missoula medical director).

In Helena, the behavioral health director described creating new meetings and enhanced communication to keep track of the most at-risk patients. With this improvement, he also hopes to decrease stigma, by treating MAT patients like any other patient and stimulating autonomy among cohorts of MAT patients. The Missoula medical director described a more intense meeting schedule that encompasses better collaboration between medical, nursing, and counseling. The WMMHC behavioral health director described a complicated reporting structure that may impede the organization's ability to solidify a fully functioning MAT team. Other participants described challenges and suggested ways to improve team collaboration. For instance, staff at several WMMHC sites described a need for more staffing:

I guess I would change the MAT team in the sense that I would make it bigger so we could actually be more effective. I don't feel like we have a team. I feel like I have me and a provider now. Even when we had our therapist, we definitely worked together in regards to our MAT people, but I just didn't feel like that we truly have, or had at that time, an MAT team (Missoula coordinator).

Staff within WMMHC expressed a need to increase the staff-to-patient ratios and bolster collaboration among team members. Participants noted that coordination among staff members could mean the difference between whether a patient recovers or relapses and drops out of the program. 


\section{Tracking of program activities and fidelity}

SOR sites use formal and informal tracking tools to measure program fidelity and success. First, staff use the Government Performance and Results Act (GPRA) system to formally track patients. This Bullhook RN described minor changes to the patient tracking system during the transition to SOR:

I think everyone felt like those were really manageable even in terms of the survey and the GPRA data that needed to be collected. I think what our team found was that, while initially that was viewed with the STR that was viewed with a lot of question and concern, I think as folks began using it more, the view shifted a little bit, and folks came to realize that it could be a really useful tool, not just for the information gathering, but almost the ritual aspect of having patients have to go through this more rigorous intake and survey process. So I think people come to value it rather than feel that it's onerous (Bulthook RN).

This participant stated that although staff initially viewed GPRA with skepticism, it requires a more rigorous intake and survey process that enables staff to garner more valuable information, causing them to see it as a valuable tool rather than an onerous waste of time. Overall, the changes were minor. Other staff responded favorably to the GPRA reporting features. A Missoula coordinator noted: "I really love the new process of sending me, 'By the way this person needs a six-month GPRA.' I really love that new process." GPRA offered staff an advantage when tracking the personal information and recovery progress for patients. A Polson participant described these updates similarly:

Initially it was overwhelming just because we had to go through the entire patient panel, but when we got all of that done, I really do like getting the daily, "Hey, this person is new." I would just call him and get done. It's a lot more streamline now that I don't have the entire bulk of everybody to go through. [. . .] Definitely easier now that it's not the entire patient panel. But yeah, we're getting them done now (Polson RN).

The GPRA system led to more efficient reporting, and most participants reported positive experiences using the system's features. They also reported strong patient buy-in to the new requirements.

Some participants, however, were troubled by the redundancy of GPRA with their other reporting tools. A Bullhook CEO stated: "Just the GRPA-it's just that it repeats a lot of what we're already doing. It's not that it's a bad . . . tool. It's just that a lot of those questions and things, we're already asking." As mentioned, sites do some additional formal tracking of patients that promotes access to care in a multitude of ways. For instance, this Hardin executive stated:

We did some initial surveying of patients to assess their capacity to do that kind of work, their technical capacity. And in our behavioral health clients at large, over $90 \%$ were able to do phone-based care with an app, we do a video app. But among our MAT clients, a lot of them are limited, and so we had to do much more telephone-based care with them and then make alternate arrangements for pharmacy, which our pharmacies have adapted with lots of their own innovations with curbside delivery and home delivery and things like these (Hardin executive).

By conducting a patient survey, Big Horn Valley Health Center was able to calculate its capacity for telehealth and implement other pharmacy innovations, such as curbside pickup and home delivery options. 
To understand how each site measures success, we asked questions about the additional metrics sites use to understand patient and staff achievement, and this led to responses about their informal measures of success and tracking. Staff at each site described key performance indicators as beneficial for chronicling patient success. One Polson participant stated: "Another interesting thing that we've talked about is getting off of Medicaid. Have they been able to get off Medicaid then? A job that also allows them to get off Medicaid." In other words, a patient's ability to secure a job, become upwardly mobile, and join their employer's insurance was seen as a marker of success. This Missoula medical director echoed the previous quote:

I'm looking at outcomes, and so getting someone to employment, I think, is a huge one, being fully employed. I would look at . . or getting someone in the school or moving down the road to that, I think that should be a key element for the recovery. [...] I'm also thinking involvement with CPS, Child Protective Services, once they can get their kids back into their home. [...] How many days have they had, their urines, when they've been screened, have been appropriate for what should be in there. [...] Are you engaged with counseling, are you doing group meetings, where are you at in your life? Housing, all those other important things, I think, to me, would be the real key indicators that, that's where you can actually say, here's what this program has done and here you can actually see the value (Missoula medical director).

The Missoula medical director described employment, resolution of CPS cases, number of days without a positive urine test, compliance with counseling, and stable housing as key performance indicators. Other programs track and gauge success on similar measures. This Butte participant stated:

Number of people actively in the program. We started looking more into how often they're seeing behavioral health, care management and tracking those numbers. And if it was less than quarterly, making those visits happen. I don't think we're ... Informally, we know very much. Like, "Oh, this person was able to get a job. Or this person is having a healthy pregnancy." But we don't track necessarily those other metrics (Butte prescriber).

Sites informally measure success by tracking employment and behavioral health and care management participation numbers. This Polson program manager confirmed: "Do they have a job in the end? What is being a productive member of society? [...] So, we've thought about it, but we're not necessarily formally doing an evaluation, I guess I would say. I think a tool would be awesome." Despite not having additional formal means to track success, the Polson staff has thought about broader questions of "success," and like staff at other sites they informally gauge success and measure program fidelity by judging how well patients are getting along in their lives.

\section{Program sustainability}

Staff at several SOR-funded MAT programs spoke about the future of their programs and the challenges facing their program's sustainability. The staff in Butte were particularly concerned about billing, insurance, and funding. This Butte executive stated: "So one area where there's a serious lacking is the cost of the medicine. And supplying the cost to those individuals that don't have the ability to pay for, or open insurance doesn't cover, that's always a big issue." This Butte participant noted that the clinic absorbs an unsustainable cost when providing services to patients who cannot afford to pay or are ineligible for insurance. Other programs identify billing and insurance issues as threatening their sustainability. This Big Horn program manager mentioned: "If there's a way to fund a physician that doesn't have to be billable on Medicaid time, we would see the investment way more for a behavioral healthcare 
manager rather than a peer support." When physicians are funded outside of Medicaid billing, programs can receive higher reimbursement rates for staff time and care.
And again, in terms of what we've encountered is a real willingness on the part of the administrators to be flexible to allow us to adapt as we go to, for example, with this Glendive expansion for the spoke, we were able to sort of work with folks to make the case that, temporary sort of initial allocation of funds to providers was reasonable, not going to happen for the long term, but as we initiated a new program and begin to develop and mature the practices, there's the rationale to receive support (Hardin program manager).

State funding and grants can aid the sustainability of programs; however, as the Hardin participant stated, not all programs may benefit from this funding source. Some sites might lack knowledgeable staff capable of applying for and managing these funding sources because they lack time or other factors. Sites with the resources to pursue these funding sources can enhance their program's sustainability, further separating them from programs with unreliable sources of income.

In other locations, the number of patients proves challenging. This Polson program manager disclosed: "For us to have as many staff as we have and be fully sustainable without any funding, they need a higher volume of patients. So yeah, expanding to more patients." Polson requires a higher patient volume to achieve program sustainability. The challenge to remain sustainable at low-volume sites differs from Polson's problem in their ability to access medical providers. This WMMHC participant commented:
Kalispell is our challenge. We have a challenge in that having a med provider up there full time, we haven't been able to establish that yet. We have one APRN up there who can prescribe, but she also has a lot of other duties with outpatient, managing crisis homes, and things of that nature, so what we're going to try to do, since we do have capacity, is we now have the Zoom platform. If they can identify up there that they have someone who needs buprenorphine services, we can actually manage that, based on state guidelines, to have a provider up there who states, you need this service, we can actually start getting a program going up there and then we can hire another individual to take over that program so it's kind of like we use some of our capacity we have right now to actually build a small, little... If we also get up to maybe 10 to 15 clients in Kalispell, then we can turn it over to a new group, new prescriber (Missoula medical director).

Sites with a low patient volume report difficulty retaining waivered prescribers and a need to collaborate with hubs for their service providers. However, the hub-and-spoke relationship does not always work as designed, as this Blackfeet health director noted:

They're doing it here in Browning, then all the patients that go to Kalispell and Cut Bank will have to use this program. Because the way Medicaid works is it's the closest one is what they'll pay for. The closest service. So if you're from Browning and you're trying to use the Kalispell service, you'll now have to use the Browning. If you're using the Cut Bank, you'll now have to use the Browning. So the last I heard there was like 160 some patients that went to Kalispell [CMS site] and I never did get any of the numbers that go to Cut Bank (Blackfeet health director).

Medicaid's billing structure may affect the sustainability of programs as their billing structure enables and constrains patients' access to services at clinics across the state.

Some staff commented on activities, committees, and meetings that enabled them to provide quality services to their patients. Staff viewed the quality of the services they provided as a facilitator in program sustainability. One Butte RN commented: 
I participate in the once-a-month MAT chat with Dr. Nauts and Tammera and all those who participate in that. I really think that they're wonderful. They're very interactive. When we've had some challenging patients that we are kind of uncertain of where to go from here with, we bring that up. Even if we know ahead of time, we email Tammara and Dr. Knotts, and then that'll be the first thing that we discuss. If you have something that's a little bit more urgent that you didn't get to email them about ahead of time at the end of the MAT chat, they always bring up, "Is anybody having cases they want to review?" So it's good because I get to hear all the other clinics reviewing their cases as well, and that is really good. Then Dr. Knotts sends out pearls of wisdom, seems to be about once a month (Butte RN).

The monthly SOR MAT chat serves as a professional development opportunity, empowering sites to review their cases, hear about patients at other sites, and learn from a cohort of professionals working on MAT across Montana.

\section{Outreach and local awareness}

Many SOR sites launched local public awareness campaigns about addiction and the services offered at their SOR sites. A Polson care coordinator commented: "We've done a lot of outreach through [Open Aid Alliance], and they have a big poster with our MAT program's information, band-aids, pens, brochures." This participant described the outreach and advertising campaign the Polson MAT program undertook to bolster its visibility and increase referrals. Other sites took similar actions to increase visibility, one Blackfeet manager noted:

Anna and her crew did a lot of media: they did radio spots, they did posters. They went from program to program explaining what their program was about. They went before our council. They just got the word out there, they got their own Facebook page, [...] presentations to the community to let them know what our program was about (Blackfeet manager).

The advertising campaigns markedly increased the visibility of the programs for patients and community members. The Blackfeet manager described an extensive media campaign, public outreach to tribes and educational institutions, and presentations to the local housing authority. Some roles, such as the Blackfeet peer support position, try to meet the community's needs by letting them know the program's goals and mission. Efforts to do this are likely getting easier, as the Blackfeet peer support specialist noted: "In the beginning, it was just, nobody wanted to give the clinic or the program a chance. That's changing, though."

As some aspects of community outreach and public acceptance change for the better, other programs report challenges when reaching out to residents, communities, and potential patients. Rurality, isolation, and a lack of community may play a role in the lack of connection SOR sites galvanize locally. One Ashland provider commented: "I think it's more due to isolation. I am finding is most people in our community are not aware. They're just not aware that there's even a program that exists." The potential lack of awareness and lack of interest in rural areas leads to potential underuse of the available services. In other cases, some staff report being too busy to advertise. One Butte provider stated:

Overwhelmed. Yeah, I think so because our MAT providers are very busy in their primary practice that are also taking this on. So that's me, I'm very busy with my own primary care practice, and I do this in addition to so that's what makes it complicated. Yeah, we could take it right on if we had someone that was solely a MAT provider, but we're just doing different things all the time (Butte provider). 
This participant, like staff at several STR sites during the previous evaluation, resisted advertising owing to other obligations. Interestingly, however, one member of the research team has heard a radio advertisement for the Butte program on several occasions. Thus, although balancing primary and secondary job responsibilities remains a challenge for staff, it is one that the Butte staff is tackling and adapting to with this round of SOR funding.

\section{Patients' perspectives on awareness and outreach}

One consistent theme among all patients, across all SOR sites, was the perception that programs are clandestine and that word of mouth is the only way to learn about them. Many patients suggested advertising the program so more could access their services. One patient in Missoula stated: "I didn't have any idea about it. [. . .] My mom was considering doing it even because she was on pain pills, she's off of them now, but she was considering doing it, and she had never heard of it except through me." This patient described having little knowledge of the program before being admitted and relaying information about the program to her mother, who was totally unaware of the program's existence. Another patient in Hamilton had a similar comment: "They don't advertise it here. I have lived here for quite a few years . . .10-15, and I never really knew that there was a Suboxone program here. I knew there was one in Missoula, but not here. So, I think it should be advertised." Many patients wanted to increase the program's visibility and knowledge, which they also believed would increase access. Another patient in Big Horn stated:

If there was a way that they could bring people in, if there was a way that they could reach out to drug addicts, maybe that's something they can improve. Reach out to them before they get started on the program to get them in to get started on the program because it's wonderful for me. [...] Stress the severity of how... They're very secretive. They're very secretive, and that is what drug addicts really ... That's the first thing they look for. They think nobody knows what they're doing. Everybody knows. They just think nobody knows what they're doing, and they're just doing it in secret. If they could reach out to drug addicts and stress the importance of the secrecy, instead they withhold it and how welcoming they are. They could just reach them (Big Horn patient).

In addition to publicizing the program, this patient suggested employing an outreach campaign to reach people struggling with drug addiction. The respondent also described how being secretive about the MAT program contrasts her experience with staff who are welcoming and helpful.

As several staff in the previous sections mentioned, programs struggle to balance increasing demand with their current staffing, so advertising the program may lead to long waitlists. Although lack of publicity and knowledge about SOR programs can prevent potential patients from accessing treatment, so too can advertising. This Bullhook patient described waiting months to gain admission:

Like I said I was on the waiting list for five months before I got on there. Make it so it's not so tough to get on the program because there's a lot of addicts out there that are trying to recover, and they can't get on the program because the waiting list is so long or they're not taking any patients. [. . . Y You need more doctors. More doctors and more nurses which I get it's tough, in a little town but I mean when the program's here and I know there's one in Chinook which is 20 miles away and then Rocky Boy, which is on the reservation, which is like 30 miles away. There's so many people in this small town that can't even get on the program. And they're suffering, struggling to get by, when they're sick, it's hard for people to get on the program. [...] Yes. I've had a few friends that . . Actually, I have a friend that just, she actually couldn't get on the one at Bullhook but she was able to get on Ideal Option, and she's been trying, she just 


\section{has a tough time with the insurance situation. She just wasn't able to get MAT at Bullhook because, like I said, they're not taking new patients (Bullhook patient).}

This patient sympathizes with rural Montanans struggling with drug addiction who lack access to MAT. Her friend's experience trying to enroll, lacking the right insurance, and settling for Ideal Options encapsulates many experiences across Montana. Another Bullhook patient described the long waitlist. A patient in Missoula described another prohibiting factor: "Them saying, 'Oh, we'll help you apply for Medicaid.' That still takes weeks, man. That could be the difference between someone overdosing and losing their life completely versus maybe being a recovering addict." This patient described a gap in care between when potential patients present to staff with their addiction and when they receive care. As these patients recounted, unfamiliarity with programs, long waitlists, and a lack of insurance can delay a potential patient's recovery process.

\section{Maintaining Community-Level Partnerships and Coalitions}

The transition from STR to SOR occurred rather smoothly, as program staff across the state described a burgeoning patient population interested in the program. Staff spent less time during the SOR phase of the project recruiting patients and more time networking with local organizations that could refer patients to the program. These relationships were both formal and informal connections within emergency departments; the criminal justice system, including jails, police, and drug courts; CPS; and other agencies such as tribes, providers, and needle exchange programs.

\section{Emergency departments}

Participants at several sites across the state described mixed results when trying to collaborate with emergency departments. A prescriber in Butte relayed the challenge she faced trying to build a referral network: "We went to our ER and they were just like, 'No, we don't see overdoses here. We just don't have it here.' 'Do you have people come in asking for pain pills?' 'Well, yeah.' 'Do you ever see overdoses?' 'Well, yeah.' It's like, they didn't see it as a problem, which was interesting." The prescriber in Butte discussed how the most effective MAT programs established relationships with their local emergency department, but despite trying to establish a rapport, emergency department staff did not see the occurrence of overdoses and pill-seeking behaviors as a need for concern or reason to collaborate.

The MAT team in Miles City corroborated this experience: "I've been trying really hard to get in the ER, actually into the hospital as a whole... I'd say nine months, if not more. We have a presentation made up but it's almost impossible. [. . .] It's just kind of fallen on deaf ears." In Miles City, MAT program staff created a presentation about induction and collaborating with hospital staff to create a referral network but achieved little success. MAT programs face a challenge in establishing reliable referral networks with emergency departments, sometimes owing to the negative perceptions emergency department staff formed when collaborating with other treatment programs.

A Hardin executive relayed: "Their experience was shaped by exposure to another program, blah, blah, blah. And so with that hospital, we've had to really pull back and just sort of focus just on the education and outreach, and we're not going to push the ER inductions." MAT staff consistently weigh the best approach to solidifying outreach and education networks, and in some cases a program's persistence will galvanize a beneficial relationship. A Butte executive stated: "[The ER] have a liaison that was coming once a month before COVID as a liaison to our medication-assisted treatment group, to our MAT meeting. So, they are very supportive. [. . .] 
It's more the providers would rather send us the patient, not have to prescribe Suboxone." In this case, Butte's MAT program eventually established a working relationship that benefited both the emergency department and the MAT program: the emergency department was able to refer patients to the MAT program and avoid inducing patients, and the MAT program had established a reliable network for gaining patients.

\title{
Criminal justice (jaill, drug court, police)
}

Many programs reported more easily establishing a rapport with individuals and agencies within the criminal justice system than within emergency departments. In the previous section a Miles City MAT team member described difficulty collaborating with local emergency departments but here stressed: "We have really good communication with probation and parole here. They do a lot of referrals for their inmates and stuff coming out of prerelease and needing to get some extra support. So, they've actually been really good." A Butte executive corroborated this statement and discussed the potential to expand within the criminal justice system: "The largest area for us is still in the justice system. [...] So that's an area that we have a lot of room to grow." Other programs stressed the importance of collaborating with probation and parole and the newfound rapport that MAT programs had developed with these agencies, as this Bullhook executive stated:

\begin{abstract}
Working with the treatment court, and then probation-parole, I think they're accepting it a lot more to where before they were like, "Suboxone? No." But I feel like they're a whole lot better, and hopefully, with treatment court, we can start people with the Suboxone too, and I think with the new judge that's coming on board, I think she'll be okay with that. [...] Yeah. I have a unique perspective on this because my husband is actually the team leader of the drug task force in our area, and I know that before Bullhook started the MAT program and people in our community were actually going 120 miles south to Great Falls for Suboxone, he was not on board because he was seeing a lot of it come up here. There wasn't the, I guess, wraparound care for those folks, and so when he found out that Bullhook was going to be taking on a MAT program, he was just like, "You guys are crazy." And now, when you talk to him, he is actually really appreciative of it because he's seen a lot of folks that he has dealt with over the years that are actually doing better now. And so, I think that that has changed his perspective a lot on it, and law enforcement as a whole, because they actually know that we're having these folks come in twice a week and we're counting their strips, and they're getting services and stuff like that, so they're not seeing it being sold on the street as much (Bullhook CEO).
\end{abstract}

Staff at the Miles City location forged relationships with probation and parole, resulting in a solid referral network for prospective patients in prerelease. In Bullhook, the SOR site has changed how members of the criminal justice community view recovery: it is seen more positively now that there is a local clinic. The Bullhook CEO described how staffing changes within drug courts can affect the referral system, but the current working relationship is strong, and that collaboration should continue.

Staff at some sites said that further collaboration with members of the criminal justice community would promote progress in the lives of their patients. A LAC in Helena stated: "It would be so beneficial to have a MAT program inside the jail. One of our gals ... had to go to jail for old charges. First day she got out, she used. And then came back to the MAT program." This participant highlights a gap in service throughout Montana: initiating a MAT program within corrections would stabilize a portion of the patient population, reduce relapses, and promote health and well-being as they transition in and out of the correctional system. The Polson care team member mentioned: "We actually have a better chance of getting in with the 
tribal jail, but our CSKT ${ }^{2}$ have a program of their own, so they'll probably work on that themselves. But it would be cool to get in with both the jails here." Formal and informal relationships determine whether patients involved in the criminal justice system continue treatment at SOR MAT programs; however, the Department of Corrections' rules and regulations also enable and constrain a patient's ability to remain in treatment.

\title{
Jail collaboration
}

All sites reported efforts to improve coordination with local detention facilities. The extent of these efforts varied considerably. Some SOR sites had a formal relationship with jails, while others had informal bonds with staff at the local detention facility. Both arrangements facilitated treatment and patient involvement in the program. The most formal agreement was reported by Helena Indian Alliance (HIA) and the development of the Bridges program embedded within the Lewis and Clark Detention Center. One Helena staff member commented:

\begin{abstract}
Well, okay. So I would say we have a heavy involvement with people in the criminal justice system, both probation and parole and Pretrial Services, and just like law enforcement in the community. And so, we've had an ongoing very good relationship with Pretrial Services. We just are really, really getting a good program going, it's called the Bridges program, with the jail. So we are working with the jail MAT ... Well, she's an MD. Her name's Courtney. So we have a process now in place where we will go pick someone up from jail and drive them right to our front door to get started on the MAT program when they get out. And so, that's called the Bridges program. So I feel like we're definitely in the beginning processes of working really well with the jail (Helena LAC).
\end{abstract}

A provider in Ashland commented on efforts to galvanize a formal relationship with jails: "Criminal justice, again, is something that is on the radar. One of our goals for the program, and this goes to some grant stuff, but it is a goal for the program, is to do some outreach to the jail system." The Helena LAC reported a strong, formal relationship between HIA and the Lewis and Clark Detention Center, while other sites, such as Ashland, report ongoing efforts to create formal ties with jails. More common than formal relationships were informal efforts. At the Blackfeet site, for instance, staff had informal relationships with the tribal justice facility intended to improve care for people transitioning out of incarceration or for those who were enrolled in a MAT program and then became incarcerated. One Blackfeet RN stated:

Yes, we actually do. So as long as the detention center allows, we actually go and deliver medication and observe the patient take the medication. [.. .] And the jail nurse, she called us up. We have a really good relationship, which is also really important because they can choose not to have us come in. That's really important for the clinic and the nurses also to build that rapport (Blackfeet RN).

This Blackfeet nurse described the informal collaboration between the MAT site and the detention center. As the nurse stated, detention center staff do not need to allow them to provide services; this cooperation is a product of the strong relationships SOR staff forge with staff at the detention center. Thus, treatment may prove tenuous when detention center treatment hinges on informal collaborations between SOR and detention center staff. Other sites report having trouble collaborating with local jails. Once incarcerated, patients lose their Medicaid benefits, presenting a barrier to continued care, especially in areas where jails have a tight budget. Cost was a critical barrier in Polson, as this staff member noted:

${ }^{2}$ Confederated Salish and Kootenai Tribes 
They're really amazing, so we're super lucky there. In terms of getting into jail, that's a different story though because of cost. Our county jail is barely functioning on the budget that they have, so the cost of the medication is just causing a lot of problems there. I think they would be open to it if there was a way to get the medication paid for (Polson care team member).

SOR sites are creating formal and informal collaborations with jails across the state. One of the barriers to this collaboration is billing and the lack of Medicaid insurance for incarcerated populations. The lack of funding mechanisms designed to pay for and reimburse detention facilities and SOR sites for medication and treatment among Montana's incarcerated population acts as a barrier to providing consistent care. Some sites have pursued strategies to ameliorate the funding issue. SOR staff are actively pursuing innovative funding mechanisms to pay for the treatment of justice-involved individuals with the SOR grant funds. While some people within the correctional system are advocates for treatment, others present barriers to program expansion owing to a "correctional point of view."

\section{Working with drug courts}

Some SOR sites, such as Blackfeet, are actively pursuing collaborative efforts with local drug courts to provide care for patients involved in the criminal justice system, while others are actively working with their local drug courts. One thing that emerged from our interviews was how judges directly affect what medications are and are not permitted under the drug court's orders. One member of the Bullhook care team said:

And then I have heard from other communities that sometimes the judge sort of mandates only certain types of medication for folks that come through drug court.

\section{[Interviewer] And they're only allowing Vivitrol?}

Correct. Vivitrol and oral Naltrexone. They just do not allow, you can't use Suboxone. You can't do any of that stuff. They're very limited about any of the stuff they use. Like, a lot of my Suboxone patients, part of the reasons they started using, abusing opioids was chronic pain issues. And those who are on the drug court, they can't have anything like Gabapentin, Lyrica, nothing (Bullhook care team member).

Staff in Butte relayed a similar experience with their drug court judge:

Drug court, the local judge in our town is very much opposed to Suboxone. A lot of drug courts around the country have the perspective of, "Oh, you're just exchanging one drug from another." There's really fascinating articles about how the manufacturer of Vivitrol has weaseled its way into a lot of drug courts, directly. Where, the judges are actually mandating treatment from the bench. So our drug court will not let us use Suboxone on patients (Butte prescribing provider).

Staff at SOR-funded MAT sites expressed that the most consistent challenge when engaging with the criminal justice system consisted of the limitations placed on medications by drug treatment court judges. The restriction of certain medications, such as buprenorphine, despite clinicians' recommendations based on an assessment of the patient's best interests, fostered a contentious relationship between providers and drug treatment court orders. A Butte executive suggested: "I would include Suboxone on the DOC formulary." Restricting the use of buprenorphine was not universal-the care team in Polson reported positive and effective coordination and collaboration with their treatment court. One member of the Polson care team stated: 
[Interviewer] The drug courts limit the specific medications that individuals can use. Is that true for you guys or no?

No, they leave it up to us. [...] Drug court has been amazing. We get patients from drug court pretty consistently. Basically they have to be in drug court in order to get their referral to us. I mean they sometimes hear it through the grape vine, and they get in with us rather than drug court, and still end up going to prison often times unfortunately. But we have really supportive district court judges. Both of them here are pretty amazing when it comes to treatment of addiction, and trying to keep them out of prison, get them treatment, get them help (Polson care team).

SOR staff in Polson reported that drug treatment court judges encourage providers to prescribe medications at their own discretion, including Suboxone. Staff in Polson also noted that the local drug treatment court judges have not required them to taper their patients' dosages. The variation in drug court orders across the state poses a barrier to consistent care across the state of Montana.

\section{Other collaborations: CPS, tribes, Ideal Options, and needle exchanges}

Many participants described broad working relationships with several stakeholder groups. In addition to emergency departments and criminal justice representatives, participants worked to forge relationships with CPS, tribes, other providers, and needle exchanges. Staff described collaborations with other providers to ensure that patients do not endure a lapse in coverage. A member of the Bullhook care team stated, "We haven't had a lot of problem with Ideal Options getting their medical records. [Patients are transferring] not because they're not doing well in the program, but because transportation is a big issue for them." Participants previously mentioned that the distance patients must travel from Havre to Great Falls impedes their recovery. But the relationships staff forge with other agencies do not always lead to the most productive working relationships. Two Blackfeet participants expressed differing opinions on the viability of working with CPS:

So we're working with everybody, with CPS, we work with $\mathrm{IHS}^{3}$, we work with the tribe. So we're pretty broad. We don't have to require so many documents that the client gets frustrated. So we do the tribal ID, and we try, if they're not on Medicaid, we have access to the portal to check and see if we can get them activated if they're non-active (Blackfeet LAC).

The willingness of agencies and staff at those agencies to work with MAT staff depends upon one's own relationship network. The Blackfeet care manager described the relationship with CPS as tenuous: "My honest opinion, I honestly don't think they [CPS] have really taken the initiative to really understand our program. [.. .] I don't see a good working relationship." This participant wanted more communication and transparency, especially around reunification plans between parents and children; the inability to receive a reunification plan inhibits the development of a care plan that includes CPS's requirements.

Participants also described some working relationships that developed by chance and needed more investment. Some participants described needing to revisit topics that community stakeholders had vetoed long before the MAT program established its reputation. A member of the Bullhook team stated:

I feel like when the Suboxone program started we had a lot of negative stigma, a lot from the $\mathrm{PD}^{4}$, and even other clinicians in the community, but we've come

${ }^{3}$ Indian Health Services

${ }^{4}$ Police Department 
a long way since then. I feel like we've run our program very well, like other clinicians have told us, "We want our programs to mirror your programs" or "We know you'll really keep them on the straight and narrow" or "You do all that you can to make sure we're not diverting." So it might be worth re-discussing a needle exchange at some point. That was shut down and pushed out of everyone's minds. Maybe it was just too much at once, we're going to get a Suboxone clinic going, and a needle exchange (Bullhook MD).

This participant described how many community stakeholders were slow to embrace the MAT program, resulting in challenges when trying to implement broader services, such as a needle exchange. Staff may need to bolster trust and then expand resources and implement controversial programs, such as needle exchanges, over time.

\section{Patients' perspectives on needle exchanges}

Patients discussed the shortcomings of the harm reduction model throughout the state of Montana and the need for needle exchanges. Several patients discussed the lack of clean needles and limited options for obtaining them. One patient in Hamilton suggested:

I think every town needs a needle exchange; I think stuff like that's important for just the community in general. [...] We're in Hamilton, but there is one an hour away in Missoula. I think there's only two or something in the whole state.

\section{[Interviewer] What would the needle exchange do?}

They'll give you hazard boxes to put your needles in. They provide you needles; they'll provide you hand sanitizer, alcohol swabs, even condoms. Just protection for everything. They do HIV/AIDS testing for free, right there (Hamilton patient).

This participant advocated for the health and well-being of people struggling with addiction through a harm reduction strategy that does not exist in Montana: needle exchanges. She described the care at needle exchanges as integral to public health and different from Montana's current model. In contrast, a Butte patient described what it is like without a needle exchange:

\section{[Interviewer] Can you tell me about what it's like to get needles in Butte?}

Oh, terrible. Disgusting. Pissed off. I think they need to be out more. Very irritated-coming from a guy that has hepatitis C and doesn't want to spread it around, they sure as hell make it fucking easy, you know? And it's sad. Yeah, it's so hard, it's so stressful. It just makes it where almost sharing needles are easier, and it's sad and it's wrong, and that's just how it is, you know? [...] And see what happens is it's a black market here now. You know, people want to make money off it because it's so hard to get (Butte patient).

This participant was clearly frustrated and upset by the lack of clean needles in his community. He described testing positive for Hepatitis $\mathrm{C}$ and to sharing needles because of a lack of options. This highlights a major public health issue within Butte and across Montana. In fact, the participant went on to describe unforeseen health problems from sharing needles, such as: "I've actually got lucky and had needles break in my arm and was able to push it out before it actually got in my fucking system and killed me." At the end of the interview we debriefed and discussed the scarcity of needle exchanges and the testing strategies exchanges use to detect lethal amounts of fentanyl. He was surprised to learn that some needle exchanges test heroin and provide a safe space for people to inject to ensure it is not laced with a lethal dose of fentanyl. To this he replied, "No, dude. We need that. You know, just recently we had a bunch of people die in Butte over bad-laced heroin. That's sad." 
Increasing resources external but complementary to the program, such as needle exchanges, would heighten the profile of the treatment options in the community and contribute to the broader harm reduction model. 


\title{
SECTION III. COVID-19 ADAPTATIONS
}

A few notable changes occurred to SOR programs as a result of the COVID-19 pandemic. Social and physical distancing restrictions prohibited patients from visiting health centers for recovery treatment, and this changed how group therapy programs functioned. One Helena LAC stated: "During the COVID stuff we stopped doing the group, and our clients started reaching out to each other and sharing their phone numbers, 'Hey, if you need anything, get ahold of me. We can talk.' Which was really cool." Thus, MAT patients rallied together and formed their own informal peer support networks as COVID-19 restrictions dissolved their common social bonds. The pandemic had other inadvertent effects, as this Missoula participant described:

\begin{abstract}
Well, at this point, because of COVID, I don't feel nearly as overwhelmed, but pre-COVID and what we will go back to, I was very overwhelmed. And a lot of that demand was that my patients dropped in a lot unannounced without appointments, and I'm certainly not going to not meet with them. [.. .] So to be doing all the orders, all the monitoring, all the administrative-type duties, all the intakes, just everything that had to be done, and having a very steady dropin of people, it was very overwhelming, and I felt like I floundered a lot. But, as far as the job itself, it finally feels doable (Missoula coordinator).
\end{abstract}

The lack of face-to-face patient engagement had the inadvertent effect of decreasing the time constraints placed on staff throughout the day. Without patients stopping by through the day, the Missoula coordinator was able to prioritize many of the administrative duties that would normally be secondary concerns when patients are in the clinic. COVID also changed the recruitment and expansion of services some programs had envisioned. One Bullhook participant commented:

Prior to that we had, we were working to increase availability of services. We reached out to the hospital and did a presentation on what we have to offer here, how they can refer clients to us, to help increase our program. When we first started, we were very strict on only taking people in our county or in our city limits to allow us to grow our patient panel slowly. There was only me and a family NP doing it. So within the past year, we've gotten two more providers waivered with the intent of taking on a lot more clients and providing more availability or access to Suboxone and Naltrexone. We unfortunately haven't been able to do that since COVID happened, we've been shutting down, locking down, only taking patients on a very as-needed basis. They haven't been growing quite as much as we thought or would like to (Bullhook MD).

COVID-19 stifled the expansion efforts the Bullhook site had planned and implemented. Instead of recruiting patients through the hospital and nearby counties, as originally planned, the site closed their doors and admitted only local patients experiencing the direst circumstances.

\section{Telehealth expansion during COVID}

To improve the availability of services, some SOR MAT sites implemented telehealth to increase access and diversify how patients and staff communicated. This was particularly true at the outset of the pandemic. One Hardin executive stated:

And in our behavioral health clients at large, over $90 \%$ were able to sort of do phone-based care with an app, we do a video app. [...] I don't think it's going back to the old way. There's so many reasons why this is just sort of breaking through barriers that shouldn't have been there in the first place. And I think we're going to have to refine and figure out in which instances 
essentially virtual MAT works well versus how do you predict in which case it's going to be a fiasco (Hardin executive).

This participant described how Big Horn Valley Health Center integrated telehealth into its care plan to create access during the COVID-19 shutdown. Most of their patients have access to a mobile device that enables them to participate in phone-based care. This participant also described the need to determine which services are best suited for telehealth, as a return to the "old way" of doing things will likely never happen. The move to telehealth does pose stratification issues, as access to a mobile device, wifi, and cellular reception is not equally distributed throughout the state. A Miles City team member stated:

And then we were doing most of our check-ins on the phone because a lot of them don't have the smart phone capabilities to deal with face-to-face telehealth visit. And so that was another thing, that increased anxiety overall because of a pandemic and [...] a lot of the people in that population don't have access to those tools. [...] Or they don't want to use the data for that. They have a limited data plan (Miles City MAT team member).

This participant described the digital divide facing Miles City patients: many patients do not have access to digital recovery tools. Patients with limited resources might not be willing or able to use their data for recovery services. Other patients simply prefer in-person care, as this Ashland provider stated:

I know there's a couple of the patients that come out of Ashland that see other sites are strictly doing their care from home. It seems to work some, but they still prefer the face-to-face. The thing, I think, that we have issues with the telehealth is it's not necessarily specifically always functional. Or in our area, not everybody has access to it, so I think we're working on trying to figure out ways to get patients funding for minutes for their phones or internet so that they have the ability to stay connected with their providers (Ashland provider).

Broadband access is a persistent issue throughout the state of Montana, and adding in patients' inability to afford these services further complicates the issue. As the Ashland participant noted, many patients prefer face-to-face interactions, but this preference might be based on a lack of access or knowledge of telehealth possibilities. In other cases, where patients have experience with telehealth, they prefer in-person meetings. A Bullhook participant stated:

I think so. What we have found from the patients that transition in from other programs. Let's just say Ideal Options. They've said that coming here and doing it like this, there's more of a sense of structure and support and seeing that person face-to-face is a big plus, rather than over video. Some patients can handle the face-to-face, or the virtual versus the face-to-face, but a lot of times it's more of an accountability thing, and just having somebody to call, and not having to travel (Bullhook BH manager).

Patients that transition to the Bullhook program from other providers, such as Ideal Options, have a substantial amount of experience with telehealth. Ideal Options uses video conferencing as the primary method through which patients and providers interact. The Bullhook manager touted the sense of structure and support patients expressed as reasons for preferring in-person appointments. Across sites, there is likely to be a continuation in expanded telehealth once the COVID-19 pandemic is managed. Within the post-COVID care environment, sites may be able to identify patient characteristics that make them more or less likely to be successful in telehealth or in-person care. 


\section{SECTION IV. FEEDBACK TO THE STATE}

Participants were asked what recommendations, suggestions, clarifications, and improvements they would offer to the state. Several participants commented on integrated behavioral health and the challenges associated with providing this service. This Helena provider noted:
Substance use disorder providers are always trying to meet a balance between like, we practice integrated behavioral health and all of those sorts of things, but we also have to meet all of our standards of our state-approved substance use program. [...] And I just have always felt like there's a huge disconnect there. So it's like, our state-approved substance use program, I think is behind the curve when it comes to some of these more integrated procedures, and I feel like they're not really inclusive of federally qualified health centers or outpatient health centers (Helena provider).

This Helena provider described a disconnect between the time it takes to deliver pointed integrated health and the state-approved provider requirements. The documentation and approval processes for integrated behavioral health clash with requirements for becoming a state-approved treatment provider in ways that make it difficult to align practices.

Another working relationship at the state level that serves as a barrier to care is the relationship clinics may forge with the Department of Corrections (DOC). One Butte executive stated: "I would include Suboxone on the DOC formulary." Many state DOC-funded agencies restrict the use of Suboxone by their clientele, and as already stated, many drug court judges frown upon prescribing this medication.

Participants also commented on several federal policies that overlap with state reporting requirements. Some of these served to disincentivize MAT and restrict the medications patients are eligible to receive in the future. One Kalispell provider noted:

The one thing that always makes me nervous that the state does is ... In their prior authorization form, stating that if you were prescribed Suboxone, that the state will never, again, pay for opiates without some sort a grand exception in there. So when I start someone on Suboxone who is on Medicaid, I actually copy that into a form and I make them sign it so that they're aware. But getting someone to sign that form can be really difficult (Kalispell provider).

Thus, some patients who suffer from chronic pain or who may need surgery in the future may be reluctant to join a MAT program if staff do not assure them that the program has a pain management plan that can address substance use disorder. Interestingly, the contradiction between oxycodone and Suboxone leads several staff to question the legitimacy of federal and state prescribing restrictions. A Polson care team member stated: "Waivering restrictions. That's always frustrating, and then the limitations for numbers and having to keep track of all that stuff, whereas any provider can prescribe oxycodone. [...] Now there's so many restrictions about it."

Participants also offered suggestions for improving how certain clinical roles interact with patients and allocate time for MAT services. The Bullhook behavioral health manager stated: "Having a provider that exclusively does MAT, because sometimes it's hard with scheduling since our provider sees medical patients regularly. Krista, she's booked for the most part. I think that's a real struggle." This participant raised the point that providers forced to handle primary care and MAT responsibilities become overwhelmed. Another Bullhook participant echoed this sentiment: 
Sometimes if you're also their primary care provider and you're also their mental health provider, just like all patients, right, they come in and they, oh I want to talk about this and this and this, and then instantly it went from a 20minute to a full 40-minute internal medicine visit that you, of course, didn't have scheduled (Bullhook care team member).

Providers tasked with providing integrated behavioral health may not be able to focus on the reason for the scheduled visit owing to more immediate patient concerns. These services often overlap, and having a provider knowledgeable about a patient's other concerns and ailments may be more beneficial for that patient in the end. This healthcare method takes more time to offer-time providers often lack. The roles staff play become challenging when staff fail to understand or recognize the roles of their teammates. A Polson care team member stated:

I mentioned this last time when we had a telephone call with Tammera. If we could make sure that the verbiage is that for our alcohol use patients that made it seem like we weren't able to use Shelby because her position is grant funded, that she could not offer her resources and assistance for alcohol use patients because they weren't opioid use disorders specifically. If there's any way to make that a little bit more flexible, so just more of a broad addiction population? (Polson care team member).

Creating flexibility within the billing structure to ensure care coordination can be more broadly used to support people suffering from substance use disorders other than OUD would ensure that more people suffering with substance use disorders receive the best care available. Billing recommendations emerged as a prevalent theme that MAT staff would make to the state. The fungibility of the billing structure concerned several participants:

Well, this is a little bit specific to kind of our situation, but, you know, AMDD, they changed their billing procedures last fall to a bundle billing or a global billing process. Which is something we're strongly supportive, but there's a few details about how they did it that are rather onerous. That would be nice if we could change them. It's simple things like having to do with, you know, they have a 30-day period, which is very difficult to keep track of, and everybody needs to have their vital signs checked at each visit, which is kind of, we feel is not necessary. I mean, some little details that we would like to tweak on that (Blackfeet prescriber).

A Polson program manager stated:

I guess one of the things that I find challenging about this grant is that the rules are ever changing. There's another grant that I manage, it's through the Montana Mental Health Trust. We had a set amount of money, and the rules were in place from the beginning. This one, the rules are ever evolving, just in part because of the nature of the program. As you're able to secure Medicaid to fund that, then those rules change. So the world's forever changing, I guess. [. . .] One other thing that we've become aware of too is just this whole change with the billing, in terms of licensed addictions counselor, and I know like Blue Cross Blue Shield is the first one that's saying, after September of this year, unless you have a master's degree, LACs aren't going to be able to bill for services (Polson program manager).

A member of the Polson care team recounted:

So I always feel like the state could do a better job in terms of maybe updating their requirements for the state approval for substance use disorders, which we're required to have because LACs can only... We're required to have that for LACs to bill for services (Polson care team member). 
The Polson program manager and care team member expressed concern about billing and policy changes that may affect the staffing and billing structure for their LACs. A yearly update about billing rules and procedures might be valuable as part of a Technical Assistance. Some staff offered other suggestions, such as providing additional tertiary funds for peer support activities. The Polson program manager stated: "Being able to meet somebody for coffee, or just having money that [peer support] is able to access to be more in the community and be able to meet people places-most of these people can't afford a cup of coffee." Allowing for more flexible spending within the program would provide peer support with more access to social engagement possibilities. 


\section{CONTACT INFORMATION}

Matthew R. Filteau

matthew@jgresearch.org

Brandn Green

brandn@jgresearch.org 